Portland State University

PDXScholar

3-2-2018

\title{
Human Resource Analytics: Implications for Strategy Realization and Organizational Performance
}

Xylia Kathleen M. Lydgate

Portland State University

Follow this and additional works at: https://pdxscholar.library.pdx.edu/honorstheses

Let us know how access to this document benefits you.

\section{Recommended Citation}

Lydgate, Xylia Kathleen M., "Human Resource Analytics: Implications for Strategy Realization and Organizational Performance" (2018). University Honors Theses. Paper 508.

https://doi.org/10.15760/honors.513

This Thesis is brought to you for free and open access. It has been accepted for inclusion in University Honors Theses by an authorized administrator of PDXScholar. Please contact us if we can make this document more accessible: pdxscholar@pdx.edu. 
Human Resource Analytics:

Implications for Strategy Realization and Organizational Performance

by
Xylia Lydgate

An undergraduate honors thesis submitted in partial fulfillment of the requirements for the degree of

Bachelor of Arts

in

University Honors

and

Business Administration: Human Resource Management and Marketing

Thesis Adviser

David E. Caughlin

Portland State University 
HR ANALYTICS AND STRATEGY

\begin{abstract}
Human resource (HR) analytics continues to attract significant attention from organizations worldwide as the HR profession is being held to a higher standard in terms of data-driven decision making and strategy realization. This paper defines HR analytics based on a thorough review of 71 sources and offers a foreground for understanding the role it plays in strategy formulation and implementation across business. A total of 9 case studies will be integrated throughout the body of the thesis to further contextualize its practicality and impact on US-based firms. The primary objective of this paper is to demonstrate that HR analytics continues to make progression in both the literature and real-life business cases. I recommend that future research address the skills and competencies required for the practice of HR analytics as well as identify the best practices and principles of an effective HR analytics function.
\end{abstract}

Keywords: human resource analytics, strategy, strategic human resource management 
HR ANALYTICS AND STRATEGY

\section{Human Resource Analytics: Strategy Realization and Firm Performance}

Increasingly, many companies offer employees benefits and perks, such as an all-youcan-eat assortment of free food, an open-pit barbecue shack, sushi and juice bar, ice cream cookie bakery, unlimited snacks all day (Sullivan, 2013), full-coverage pet insurance (Jenks, 2017), $\$ 4,000$ in "baby cash" for soon-to-be parents, or even a $\$ 2,000$ bonus each year to travel anywhere in the world (Smith, 2016). The purpose behind these incredible benefits and perks extends beyond happy employees. In fact, successful companies such as Google, Facebook, and Apple are able to measure and evaluate the effects of such talent management practices and, in turn, make data-driven decisions to justify their returns on business performance - an approach called human resource analytics. Although it has been defined in different ways, human resource (HR) analytics refers to the practice of using data to support decisions pertaining to HR systems, policies, and practices. In a world where top management often looks to the numbers before making decisions, HR analytics represents a growing trend amongst the management field (Pfau \& Cohen, 2003; Rasmussen \& Ulrich, 2014), as the practice offers a useful framework and set of tools for measuring and evaluating the efficacy of HR systems, programs, and interventions. For instance, senior leaders who are paying close attention to the rise of big data and its impact on the field of human resources have potential to advance their organizations' productivity and profitability by up to $6 \%$ higher than their peers (Barton \& Court, 2012). Other literature suggests that measuring employee management practices is essential for driving shareholder value and positively increasing business metrics including employee growth, average profit, and revenue per employee (Bates, 2003; Pfeffer \& Veiga, 1999). 
HR ANALYTICS AND STRATEGY

According to Mondore, Doutitt \& Carson (2011), HR analytics "[demonstrates] the direct impact of people data on important business outcomes" based on empirical evidence (p. 21). Other terms that are more or less synonymous with or inclusive in the definition of HR analytics include talent analytics, workforce analytics, people analytics, human capital analytics, human capital strategy and human capital metrics, HR metrics, and evidence-based management. For reasons of parsimony, I will use the term HR analytics throughout this thesis.

It should be noted that HR analytics is more than collecting data and conducting analyses; rather, it can be used as an approach to quantify the effects of HR initiatives, influence executive buy-in, and enable cross-functional interaction amongst departments (Bates, 2003; Chadwick, Super \& Kwon, 2015; Mondore et al., 2011). Further, a variety of approaches to HR analytics and data analytics more generally - exist, and in most cases, these approaches can be categorized along a continuum of complexity, ranging in ascending order of sophistication from descriptive, predictive, and prescriptive analytics.

HR analytics is a relatively new term and reflects a multidisciplinary trend toward using data to inform decision making, as reflected in the rapid growth of data science. With that said, HR analytics has roots in industrial and organizational psychology - a discipline which has been in existence for over a century - as well as mathematics, statistics, and economics. For example, industrial and organizational psychologists have, for many decades, used data to validate employee selection tools and evaluate training (as well as numerous other practices) in organizations. Accordingly, for some organizations, the rise of HR analytics has resulted in a rebranding of an existing function, whereas in other organizations, an entirely new function was introduced. As will be addressed later in this thesis, HR analytics tends to place more of an 
HR ANALYTICS AND STRATEGY

emphasis on informing and supporting organizational strategy, and in the process, integrating HR with other business functions. Finally, HR analytics packages many data-analytic techniques and concepts into a HR-specific bundle, while simultaneously accounting for legal, ethical, and business considerations and implications.

Logically, the HR analytics function may be integrated within an organization's broader strategic human resource management (HRM) function, as one can argue that doing so may help the organization identify and develop commitment-based HR systems and high performance work practices (Chadwick et al., 2015; Combs, Liu, Hall, \& Ketchen, 2016). Commitment-based HR systems refer to heavy organizational investment in resources that support the growth and development of employees. For example, when managers implement intense, rigorous, and competitive talent acquisition practices and training and development for employees, this collection of systems and practices is often referred to as commitment-based HR systems (Chadwick et al., 2015). Similarly, according to strategic HRM scholars, high performance work practices refer to systems of practices designed to enhance worker motivation and performance, such as pay-for-performance plans and flexible work arrangements, to name a few (Bates, 2001; Combs et al., 2016). Thus, it stands to reason that HR analytics has the potential to facilitate the realization of strategic objectives and improve organizational competitiveness by leveraging data to identify and develop better commitment-based HR systems and high performance work practices. With that said, the following questions remain:

What is the current state of the science and practice of HR analytics? How does HR analytics and strategic HRM operate synchronously to impact firm performance? Does 
HR ANALYTICS AND STRATEGY

$H R$ analytics support the identification, deployment, and evaluation of high-performance work practices?

Despite the growing interest in HR analytics and the logical argument that HR analytics can be integrated into strategic HRM, relatively few empirical studies have directly investigated whether companies with a defined HR analytics function outperform those that lack a defined HR analytics function, or as Rasmussen and Ulrich (2014) stated: "the lack of analytics on analytics" (p. 237). Of course, the absence of evidence on a particular phenomenon does not necessarily mean evidence of absence. In other words, there is a gap in the literature, and more research is needed to understand how HR analytics is operationalized across organizations and under what conditions a well-defined HR analytics function contributes to an organization's performance. In recognition of this gap in the literature, in this thesis, I will be compiling and synthesizing peer-reviewed scholarly sources, practitioner journal articles, published books, news articles and press releases, white papers, popular magazines, blog posts, and case studies to clarify disparities in the differences between scholarly and practitioner literatures, and evidence pertaining to my aforementioned research questions. Specifically, I will conduct a rigorous review of the extant literature to identify how and why a HR analytics function is implemented in organizations, and the extent to which a HR analytics function can add value and facilitate the attainment of strategic objectives. To contextualize HR analytics and provide concrete examples, I will integrate case studies throughout this thesis. Case studies will be identified in accordance with literature findings and be paired alongside discussions inspired by the HR analytics discourse community. The structure of the paper will lead with a literature review methodology section, followed by an introduction that includes an in-depth definition of HR analytics and 
HR ANALYTICS AND STRATEGY

strategic HRM, as well as the state of science and practice in those areas. Lastly, I will discuss the limitations of the present review and implications for future research and practice.

\section{Literature Review Methodology}

The primary method of information gathering utilized for this thesis is an extensive literature review. A total of 71 sources published from years 1995 to 2018 were reviewed from a collection of journals, including the Academy of Management Journal, Harvard Business Review, Human Resource Management Journal, Journal of Business Strategy, People and Strategy, Personnel Psychology, and Organizational Dynamics, as well as non-refereed sources. A combination of academic databases served as the foundation for searching for and documenting such articles, including Google Scholar, Emerald Insight, GALE Business Collection, and Elsevier ScienceDirect. Thirteen sources were books on the topics of human capital, talent management, employee experience, big data, and analytics and metrics. As there is not one agreed on term regarding HR analytics in the both the scholarly and practitioner literatures, my keyword search terms included workforce analytics, people analytics, people research, talent analytics, predictive analytics, human capital analytics, human capital management, high performance work practices, strategic human resource management, employee experience, human resource architecture, human resource metrics, human resource data, and evidence-based human resources. In addition to conducting manual searches in specific databases, I searched for other related articles based on the listed citations and corresponding references of key articles, and by using the "cited by" function in Google Scholar. Relevant information from 71 sources will be highlighted in the following literature review to address my research questions. 
HR ANALYTICS AND STRATEGY

Table 1, Table 2, and Figure 1 list all sources reviewed in this paper categorized by publication type. Among the literature reviewed, peer-reviewed (20) and practitioner (15) journals were given more weight in the analysis followed by books (13). The additional 24 sources include blog posts, white papers, news articles, and popular magazines which contributed to the discussion on HR analytics, strategic HRM, and other similar topics.

Table 1. Specific Sources of Reviewed and Source Type.

\begin{tabular}{|l|l|}
\hline Source & Type \\
\hline Alharthey \& Rasil (2011) & Scholarly journal \\
\hline Angrave et al. (2016) & Scholarly journal \\
\hline Barrette (2015) & Practitioner journal \\
\hline Barton \& Court (2012) & Practitioner journal \\
\hline Bassi (2011) & Practitioner journal \\
\hline Bates (2001) & Practitioner journal \\
\hline Bates (2003) & Popular magazine \\
\hline Bauer \& Caughlin (2017) & Blog \\
\hline Beatty (2005) & White paper \\
\hline Becker et al. (2001) & Book \\
\hline Bock (2015) & Book \\
\hline Boselie et al. (2005) & Scholarly journal \\
\hline Boudreau \& Ramstad (2007) & Book \\
\hline Brown (2013) & Book \\
\hline Burris (2016) & Blog \\
\hline Carlson \& Kavanaugh (2015) & Book \\
\hline Campion \& McClelland (1991) & Scholarly journal \\
\hline Cascio \& Boudreau (2011) & Book \\
\hline Caughlin, D. E. (in press) & Other \\
\hline Chadwick et al. (2015) & Scholarly journal \\
\hline
\end{tabular}


HR ANALYTICS AND STRATEGY

\begin{tabular}{|c|c|}
\hline Combs et al. (2016) & Scholarly journal \\
\hline Davenport \& Patil (2012) & Practitioner journal \\
\hline Davenport et al. (2007) & Practitioner journal \\
\hline $\begin{array}{l}\text { Deloitte's Bersin Finds Effective Use of People Analytics Is } \\
\text { Strongly Related to Improved Talent and Business } \\
\text { Outcomes (2017) }\end{array}$ & Other \\
\hline De Treville \& Antonakis (2006) & Scholarly journal \\
\hline Dobbs et al. (2012) & Practitioner journal \\
\hline Dorio et al. (2014) & White paper \\
\hline Edwards and Edwards (2016) & Book \\
\hline Falletta (2014) & Scholarly journal \\
\hline Fitz-enz (2010) & Book \\
\hline Fitz-Enz \& Mattox (2014) & Book \\
\hline $\begin{array}{l}\text { Future Insights: the top trends according to SHRM's HR } \\
\text { subject matter expert panels (2009) }\end{array}$ & White paper \\
\hline Gale (2015) & Popular magazine \\
\hline Harris \& Light (2011) & Scholarly journal \\
\hline Heskett et al. (2008) & Practitioner journal \\
\hline Humphrey et al. (2007) & Scholarly journal \\
\hline Hunt (2014) & Book \\
\hline Huselid (1995) & Scholarly journal \\
\hline IBM Watson Talent Insights (2018) & Other \\
\hline Isson and Harriott (2012) & Book \\
\hline Jackson et al. (2014) & Scholarly journal \\
\hline Jiang et al. (2012) & Scholarly journal \\
\hline Kaur \& Fink (2017) & White paper \\
\hline Khoso (2016) & $\mathrm{B} \log$ \\
\hline Lawler et al. (2004) & White paper \\
\hline Levenson (2010) & White paper \\
\hline Marler \& Boudreau (2017) & Scholarly journal \\
\hline
\end{tabular}


HR ANALYTICS AND STRATEGY

\begin{tabular}{|c|c|}
\hline McAfee and Brynjolfsson (2012) & Practitioner journal \\
\hline Molefe (2014) & Other \\
\hline Mondore et al. (2011) & Practitioner journal \\
\hline Morgan (2017) & Book \\
\hline $\begin{array}{l}\text { New Bersin by Deloitte Research Shows Organizations with } \\
\text { High-Impact Talent Analytics Realize Major Financial, } \\
\text { Leadership, and Recruitment Gains (2013) }\end{array}$ & Other \\
\hline Pease (2015) & Book \\
\hline Pemmaraju (2007) & Practitioner journal \\
\hline $\begin{array}{l}\text { People analytics at Google: using data to make Google a great } \\
\text { place to work (2017) }\end{array}$ & Blog \\
\hline Pfau \& Cohen (2003) & Scholarly journal \\
\hline Pfeffer \& Veiga (1999) & Scholarly journal \\
\hline Rasmussen \& Ulrich (2014) & Scholarly journal \\
\hline Rousseau \& Barends (2011) & Practitioner journal \\
\hline Schiemann \& Seibert (2017) & Practitioner journal \\
\hline Sinar (2018) & Blog \\
\hline Smith (2016) & Blog \\
\hline Sullivan (2013) & News article \\
\hline Taylor (et al. 1996) & Scholarly journal \\
\hline $\begin{array}{l}\text { The Dollars and Sense of Employee Engagement, Calculate } \\
\text { Your ROI (2017) }\end{array}$ & Blog \\
\hline Thibodeau (2018) & News article \\
\hline Ulrich, Schiemann \& Sartain (2015) & Practitioner journal \\
\hline van den Heuvel, S., \& Bondarouk, T. (2016) & Other \\
\hline Walsh et al. (2010) & Scholarly journal \\
\hline Welbourne (2015) & Practitioner journal \\
\hline Witte (2016) & Scholarly journal \\
\hline
\end{tabular}


HR ANALYTICS AND STRATEGY

Table 2. Literature Reviewed by Source Type.

\begin{tabular}{|l|c|}
\hline Source Type & Number of sources \\
\hline Scholarly journal (peer-reviewed) & 20 \\
\hline Practitioner journal & 15 \\
\hline Book & 13 \\
\hline Blog post & 7 \\
\hline Other & 6 \\
\hline White paper & 6 \\
\hline News article & 2 \\
\hline Popular magazine & 2 \\
\hline
\end{tabular}

Literature Analyzed

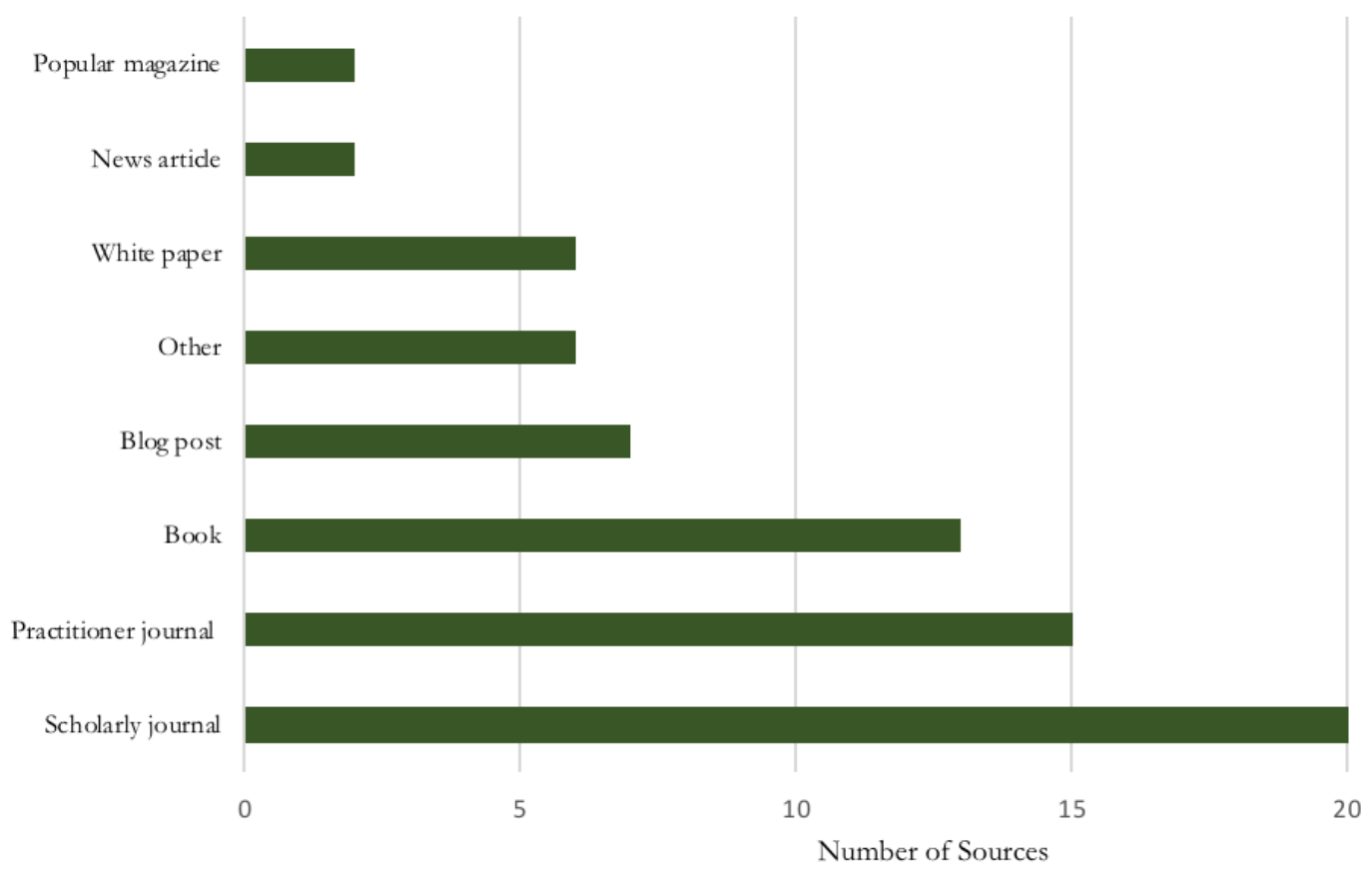

Figure 1. Bar chart of the relative number of sources per source type 
HR ANALYTICS AND STRATEGY

The specific literature selected for this review addresses HR analytics or similar concepts that contribute to the overall understanding of the function and its applications in business. The following literature review will follow a process timeline from an organizational perspective beginning with strategy formulation to strategy realization. First, I will provide an overview of the state of the science pertaining to HR analytics, including contemporary definitions and applications. Second, I will discuss the contingencies involved in building organizational support from upper management and stakeholders to support a HR analytics function. Third, I will describe the development process of a HR analytics function and the role it plays in strategy formulation and planning. Fourth, I will provide an overview of the major steps involved in implementing HR analytics within an organization. Lastly, I will summarize any literature investigating the effects of HR analytics and strategic HRM on firm performance. Concurrently, I will be making connections, identifying gaps, and drawing conclusions abfvout the literature in relation to my research questions. Upon assessing the effects of HR analytics on organizational performance, I will be considering factors such as financial gains, employee attrition, customer satisfaction, and cost savings.

\section{HR Analytics: State of the Science and Practice}

The current body of literature on HR analytics suggests that many organizations collect and/or analyze relatively few types of HR data and engage in a backwards-looking approach for reporting HR processes to executive management (Angrave, Stuart, Charlwood, Kirkpatrick, \& Lawrence, 2016; Harris \& Light, 2011; Mondore et al., 2011). In terms of the analytics complexity continuum (i.e., descriptive, predictive, and prescriptive analytics), such approaches can be categorized as basic descriptive analytics. While informative, by themselves, these 
HR ANALYTICS AND STRATEGY

approaches to HR analytics are necessary but not sufficient for developing and implementing HR systems, policies, and practices with a measurable impact on business performance. Further, they may be insufficient for convincing key stakeholders, such as executive management, to invest more resources in the HR function. This emphasis on descriptive analytics has its roots in the metrics reported commonly by HR departments (e.g., turnover rate, yield ratio) and by HR information systems. Some place the blame for the overreliance on HR metrics and descriptive analytics on the HR information systems used by organizations, as they can be limited in functionality and report solely historical information (Angrave et al. 2016). While these traditional forms of analytics may be useful for reporting, they fall short of predicting important employee and organizational outcomes (Harris \& Light, 2011). Thus, given that strategic HRM is inherently future-oriented, it stands to reason that a robust HR analytics, replete with descriptive, predictive, and prescriptive analytics, has the potential to facilitate strategy realization and ultimately improve firm performance through its influence on high performance work practices and commitment-based HR systems.

\section{Defining HR Analytics}

Prior to an in-depth discussion on the literature, it is critical to establish a common definition of HR analytics and how it differs among the discourse community. Additional terms that are more or less synonymous with HR analytics include talent analytics, workforce analytics and workforce science, talentship decision science, people analytics and people research, human capital analytics, human capital strategy and human capital metrics, HR metrics and HR architecture, talent architecture, and evidence-based HR and management. Additional terms that 
HR ANALYTICS AND STRATEGY

are related to the definition and application of HR analytics include descriptive, predictive, and prescriptive analytics.

Regarding data analytics, in general, scholars recognize that the practice and application of analytics can be defined along a continuum (Cascio \& Boudreau, 2011; Fitz-Enz \& Mattox, 2014; Isson \& Harriot, 2016; Kaur \& Fink, 2017; Pease, 2015; Witte, 2016). First, one can conceptualize two broad categories of analytics that organizations may practice: retrospective and prospective. Retrospective analytics is a backwards-looking approach for reporting historical organizational performance (Molefe, 2014). Prospective analytics is a forward-looking approach which builds upon retrospective data for making predictions about future performance (Fitz-enz, 2010; van den Heuvel \& Bondarouk, 2016).

Subsumed within the overarching categories of retrospective and prospective analytics are three dimensions of analytics: descriptive, predictive and prescriptive (see Figure 2) (FitzEnz \& Mattox, 2014; Isson and Harriot, 2016). Nested with retrospective analytics, descriptive analytics answers the question: "What happened in the past?” (Fitz-Enz \& Mattox, 2014). Descriptive analytics is practiced by using various measurement tools to conduct basic reporting, including those generated from mobile and cloud-based software programs (Gale, 2015). Predictive analytics answers the questions: "What will happen, why will it happen, and how will it happen?" Predictive analytics can be used to make evidence-based predictions about future outcomes (Bock, 2015; Edwards \& Edwards, 2016; Fitz-Enz \& Mattox, 2014). Finally, prescriptive analytics leverages predictive analytics findings to prescribe specific actions and to anticipate organizational change (Hunt, 2014; Pease, 2015). 


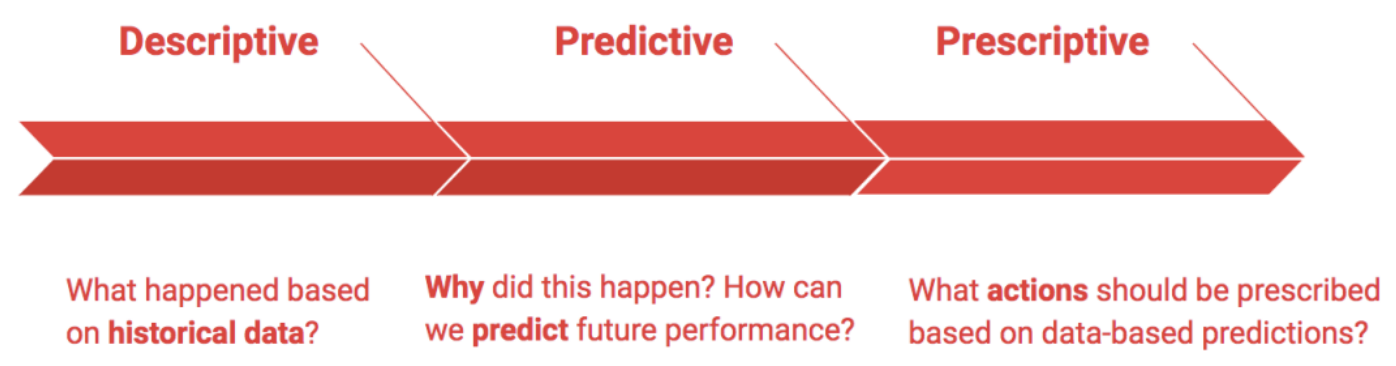

Figure 2. This figure illustrates the three dimensions of the data analytics continuum with applications to business and HRM (Fitz-Enz \& Mattox, 2014; Isson \& Harriot, 2016).

Regarding HR analytics, specifically, there is not one conclusive way to define and conceptualize HR analytics. With that said, some consensus is building that HR analytics is more than just retrospective analytics, descriptive analytics, or traditional HR metrics. Of the 71 sources reviewed, 19 of them mention HR analytics, or a similar term, but do not define it; 32 sources define HR analytics or a similar term; and the 20 remaining sources comprise of other related terms that contribute to the literature surrounding HR analytics, strategy, and its significance to the discourse community. As previously mentioned, there appears to be conflicting information (or, at times, misinformation) regarding what an effective HR analytics function looks like (Angrave et al. 2016; Rasmussen \& Ulrich, 2014). By definition, there does not appear to be a consistent way HR analytics is defined across-the-board in literature. There are a number of reasons for disparities in the definition of HR analytics. These can range from the way an organization customizes its processes to the size of an organization to the competencies of the individuals who work in the HR department (Bassi, 2011; Kaur \& Fink, 2017). Bassi (2011) highlights several important factors that contribute to the implementation of HR analytics and sets the groundwork for trending gaps in the literature. Namely, no organization is the same 
HR ANALYTICS AND STRATEGY

in the way its processes and procedures are designed. If an organization is striving to incorporate a HR analytics function, it is expected that it will look different across organizations and industries. Further, Bassi argues that the size of an organization plays a role in an organization's capacity and likelihood to design a HR analytics function. For example, as Bassi notes, a smaller company may be more concerned with the daily operations of running a business and gaining stability rather than investing additional resources in HR analytics. Furthermore, the knowledge, skills, and abilities of current HR analysts and managers - particularly with respect to quantitative skills - influence the extent HR analytics will lead to prescriptive action in support of strategic business initiatives (Bassi, 2011; Pfau \& Cohen, 2003).

A summary of the collected definitions can help business leaders and scholars alike generate a more comprehensive understanding of what HR analytics is and how it can be used to transform business decisions and performance (see Table 3). After reviewing this collection of definitions, I expand the preliminary definition of HR analytics provided in the introduction of this thesis and define $H R$ analytics as the practice of analyzing HR-related data to support decision making and implement measurable action for improving employee and organizational performance, realizing strategic objectives, and achieving and maintaining a competitive advantage. This is a comprehensive definition of HR analytics that was derived after careful recognition of patterns across 32 different descriptions of the term noted in this literature review. 
HR ANALYTICS AND STRATEGY

Table 3. Definitions of HR analytics.

\begin{tabular}{|c|c|c|c|}
\hline Source & $\begin{array}{l}\text { Mentions HR } \\
\text { analytics or } \\
\text { similar term? }\end{array}$ & $\begin{array}{l}\text { Defines HR } \\
\text { analytics or } \\
\text { similar term? }\end{array}$ & If yes, the definition provided: \\
\hline Alharthey \& Rasli (2011) & No & No & N/A \\
\hline Angrave, et al., (2016) & Yes & Yes & $\begin{array}{l}\text { Using it [HR data] to answer strategic questions about how } \\
\text { people create value for the organization, so that value can } \\
\text { be captured and leveraged (5) }\end{array}$ \\
\hline Barrette (2015) & Yes & No & N/A \\
\hline Barton \& Court (2012) & Yes & No & N/A \\
\hline Bassi (2011) & Yes & Yes & $\begin{array}{l}\text { The application of a methodology and integrated process } \\
\text { for improving the quality of people-related decisions for } \\
\text { the purpose of improving individual and/or organizational } \\
\text { performance (16) }\end{array}$ \\
\hline Bates (2001) & No & No & N/A \\
\hline Bates (2003) & Yes & Yes & $\begin{array}{l}\text { Calculating with confidence the return on investment } \\
\text { (ROI) of individual employees (1) }\end{array}$ \\
\hline $\begin{array}{l}\text { Bauer \& Caughlin } \\
(2017)\end{array}$ & Yes & No & N/A \\
\hline Beatty (2005) & No & No & $\mathrm{N} / \mathrm{A}$ \\
\hline Becker et al. (2003) & Yes & Yes & $\begin{array}{l}\text { The sum of the HR function, the broader HR system, and } \\
\text { the resulting employee behaviors (1) }\end{array}$ \\
\hline Bock (2015) & Yes & Yes & $\begin{array}{l}\text { Moving from description to analysis and insight to } \\
\text { prediction, using employee attrition as an illustration (288) }\end{array}$ \\
\hline Boselie et al. (2005) & No & No & N/A \\
\hline $\begin{array}{l}\text { Boudreau \& Ramstad } \\
\text { (2007) }\end{array}$ & Yes & Yes & $\begin{array}{l}\text { To increase the success of the organization by improving } \\
\text { decisions that depend on or impact talent resources } \\
\text { [talentship decision science] (25) }\end{array}$ \\
\hline Brown (2013) & Yes & Yes & $\begin{array}{l}\text { Calculating the knowledge and skills of the workforce } \\
\text { [human capital analytics] (215) }\end{array}$ \\
\hline Burris (2016) & Yes & No & N/A \\
\hline $\begin{array}{l}\text { Carlson \& Kavanaugh } \\
(2015)\end{array}$ & Yes & No & N/A \\
\hline $\begin{array}{l}\text { Campion \& McClelland } \\
\text { (1991) }\end{array}$ & No & No & N/A \\
\hline $\begin{array}{l}\text { Cascio \& Boudreau } \\
(2011)\end{array}$ & Yes & Yes & Fact-based decision making (21) \\
\hline Caughlin, D. E. (in press) & Yes & Yes & $\begin{array}{l}\text { The systematic and scientific process of applying } \\
\text { quantitative or qualitative data analysis methods to derive } \\
\text { insights that shape and inform employee-related business } \\
\text { decisions and performance (2) }\end{array}$ \\
\hline Chadwick et al. (2015) & No & No & N/A \\
\hline Combs et al. (2006) & No & No & N/A \\
\hline Davenport \& Patil (2012) & No & No & N/A \\
\hline Davenport et al. (2007) & Yes & Yes & $\begin{array}{l}\text { Analytical HR starts with the delivery of historical facts } \\
\text { and ends with real-time deployment of talent based on } \\
\text { rapidly changing needs (3) }\end{array}$ \\
\hline $\begin{array}{l}\text { Deloitte's Bersin Finds } \\
\text { Effective Use of People }\end{array}$ & Yes & No & N/A \\
\hline
\end{tabular}




\begin{tabular}{|c|c|c|c|}
\hline $\begin{array}{l}\text { Analytics Is Strongly } \\
\text { Related to Improved } \\
\text { Talent and Business } \\
\text { Outcomes (2017) } \\
\end{array}$ & & & \\
\hline $\begin{array}{l}\text { De Treville \& Antonakis } \\
\text { (2006) }\end{array}$ & No & No & N/A \\
\hline Dobbs et al. (2012) & No & No & N/A \\
\hline Dorio et al., (2014) & Yes & yes & $\begin{array}{l}\text { [It is] the application of behavioral science, statistics and } \\
\text { psychological principles to improve employee and } \\
\text { organizational performance [workforce science] (2) }\end{array}$ \\
\hline $\begin{array}{l}\text { Edwards \& Edwards } \\
\text { (2016) }\end{array}$ & Yes & Yes & $\begin{array}{l}\text { The systematic application of predictive modelling using } \\
\text { inferential statistics to existing HR people-related data in } \\
\text { order to inform judgements about possible causal factors } \\
\text { driving key HR-related performance indicators (2) }\end{array}$ \\
\hline Falletta (2014) & Yes & No & N/A \\
\hline Fitz-Enz (2010) & Yes & Yes & $\begin{array}{l}\text { HR analytics is a communications tool, first and foremost. } \\
\text { It brings together data from disparate sources, such as } \\
\text { surveys and operations of different units or levels, to paint } \\
\text { a cohesive, actionable picture of current conditions and } \\
\text { likely futures (9) }\end{array}$ \\
\hline $\begin{array}{l}\text { Fitz-Enz \& Mattox } \\
\text { (2014) }\end{array}$ & Yes & Yes & $\begin{array}{l}\text { HR or human capital analytics is primarily a } \\
\text { communications device. It brings together data from } \\
\text { disparate sources, such as surveys, records and operations, } \\
\text { to paint a cohesive, actionable picture of current } \\
\text { conditions and likely future. [It] is an evidence-based } \\
\text { approach to making better decisions. (3) }\end{array}$ \\
\hline $\begin{array}{l}\text { Future Insights: the top } \\
\text { trends according to } \\
\text { SHRM's HR subject } \\
\text { matter expert panels } \\
\text { (2009) }\end{array}$ & Yes & No & N/A \\
\hline Gale (2015) & Yes & No & N/A \\
\hline Harris \& Light (2011) & Yes & No & N/A \\
\hline Heskett et al. (2008) & No & No & N/A \\
\hline HR analytics (n.d.) & Yes & Yes & $\begin{array}{l}\text { HR analytics enables organizations to use their wealth of } \\
\text { employee data to make better decisions about their } \\
\text { workforces and improve operational performance. }\end{array}$ \\
\hline Humphrey et al. (2007) & No & No & N/A \\
\hline Hunt (2014) & Yes & Yes & $\begin{array}{l}\text { [It] enables companies to find, attract, and engage high- } \\
\text { quality candidates with the minimal investment possible } \\
\text { [workforce analytics] (64) }\end{array}$ \\
\hline Huselid (1995) & No & No & N/A \\
\hline $\begin{array}{l}\text { IBM Watson Talent } \\
\text { Insights (n.d.) }\end{array}$ & Yes & Yes & $\begin{array}{l}\text { [It] analyzes human resources (HR) information to help } \\
\text { you gain actionable insight, make fact-based decisions, } \\
\text { forecast impacts and discover new opportunities [IBM } \\
\text { Watson Talent Insights]. }\end{array}$ \\
\hline Isson \& Harriott (2013) & Yes & Yes & $\begin{array}{l}\text { People analytics starts with a talent management business } \\
\text { question or goal, and then integrates disparate data sources } \\
\text { together to create predictions for the future, which can }\end{array}$ \\
\hline
\end{tabular}


HR ANALYTICS AND STRATEGY

\begin{tabular}{|c|c|c|c|}
\hline & & & $\begin{array}{l}\text { then be used to outline businesses' actions with measurable } \\
\text { results (46) }\end{array}$ \\
\hline Jackson et al. (2014) & No & No & $\mathrm{N} / \mathrm{A}$ \\
\hline Jiang et al. (2012) & No & No & N/A \\
\hline Kaur \& Fink (2017) & Yes & Yes & $\begin{array}{l}\text { [It] is the attempt to understand patterns in an } \\
\text { organization's workforce through analysis of employee- } \\
\text { related data (1) }\end{array}$ \\
\hline Khoso (2016) & Yes & No & $\mathrm{N} / \mathrm{A}$ \\
\hline Lawler et al. (2004) & Yes & Yes & $\begin{array}{l}\text { HR analytics transforms HR data and measures into } \\
\text { rigorous and relevant insights. It includes statistics and } \\
\text { research design, but it goes beyond them to include } \\
\text { identifying and articulating meaningful questions, } \\
\text { gathering and using appropriate data from within and } \\
\text { outside the HR function, setting the appropriate standards } \\
\text { for rigour and relevance, and enhancing the analytical } \\
\text { competencies of HR throughout the organization (2) }\end{array}$ \\
\hline Levenson (2010) & Yes & Yes & $\begin{array}{l}\text { HCA helps tell and validate a story that illustrates the } \\
\text { driving forces behind individuals' and groups' behaviors } \\
\text { and performance (4) }\end{array}$ \\
\hline $\begin{array}{l}\text { Marler \& Boudreau } \\
\text { (2017) }\end{array}$ & Yes & $\begin{array}{c}\text { Yes } \\
\end{array}$ & $\begin{array}{l}\text { A HR practice enabled by information technology that } \\
\text { uses descriptive, visual, and } \\
\text { statistical analyses of data related to HR processes, human } \\
\text { capital, organizational } \\
\text { performance, and external economic benchmarks to } \\
\text { establish business impact and } \\
\text { enable data-driven decision-making (15) }\end{array}$ \\
\hline $\begin{array}{l}\text { McAfee \& Brynjolfsson } \\
(2012)\end{array}$ & No & No & N/A \\
\hline Molefe (2014) & Yes & No & N/A \\
\hline Mondore et al. (2011) & Yes & Yes & $\begin{array}{l}\text { Demonstrating the direct impact of people data on } \\
\text { important business outcomes. }\end{array}$ \\
\hline Morgan (2017) & Yes & Yes & $\begin{array}{l}\text { [It] gives organizations the data and the insight they need } \\
\text { to make people-related decisions. People analytics also } \\
\text { empowers organizations to test ideas and run experiments } \\
\text { (38) }\end{array}$ \\
\hline $\begin{array}{l}\text { New Bersin by Deloitte } \\
\text { Research Shows } \\
\text { Organizations with High- } \\
\text { Impact Talent Analytics } \\
\text { Realize Major Financial, } \\
\text { Leadership, and } \\
\text { Recruitment Gains. } \\
\text { (2013) }\end{array}$ & Yes & No & N/A \\
\hline Pease (2015) & Yes & Yes & $\begin{array}{l}\text { Human capital analytics is the application of sophisticated } \\
\text { data mining and business analytics techniques to human } \\
\text { resource data (110) }\end{array}$ \\
\hline Pemmaraju (2007) & Yes & No & N/A \\
\hline $\begin{array}{l}\text { People analytics at } \\
\text { Google: using data to }\end{array}$ & Yes & No & N/A \\
\hline
\end{tabular}


HR ANALYTICS AND STRATEGY

\begin{tabular}{|c|c|c|c|}
\hline $\begin{array}{l}\text { make Google a great } \\
\text { place to work (2017) }\end{array}$ & & & \\
\hline $\begin{array}{l}\text { People analytics } \\
\text { maturity: Top findings } \\
\text { from } \\
\text { high-impact people } \\
\text { analytics research (2017) }\end{array}$ & Yes & No & N/A \\
\hline Pfau \& Cohen (2003) & No & No & N/A \\
\hline Pfeffer, \& Veiga (1999) & No & No & N/A \\
\hline $\begin{array}{l}\text { Rasmussen \& Ulrich } \\
\text { (2015) }\end{array}$ & Yes & No & N/A \\
\hline $\begin{array}{l}\text { Rousseau \& Barends } \\
\text { (2011) }\end{array}$ & Yes & Yes & $\begin{array}{l}\text { EBHR is a decision-making process combining critical } \\
\text { thinking with use of the best available scientific evidence } \\
\text { and business information (221) }\end{array}$ \\
\hline $\begin{array}{l}\text { Schiemann \& Seibert } \\
\text { (2017) }\end{array}$ & Yes & No & N/A \\
\hline Sinar (2018) & Yes & Yes & $\begin{array}{l}\text { The systematic identification and qualification of the } \\
\text { people drivers of business outcomes, with the purpose of } \\
\text { making better decisions. }\end{array}$ \\
\hline Smith (2016) & No & No & N/A \\
\hline Sullivan (2013) & Yes & Yes & $\begin{array}{l}\text { People analytics produces many products, including } \\
\text { employee surveys that are not anonymous, and } \\
\text { dashboards. It also attempts to identify insightful } \\
\text { correlations and to provide recommended } \\
\text { actions. }\end{array}$ \\
\hline Taylor et al. (1996) & No & No & N/A \\
\hline $\begin{array}{l}\text { The Dollars and Sense of } \\
\text { Employee Engagement } \\
\text { Calculate Your ROI } \\
\text { (n.d.) }\end{array}$ & No & No & N/A \\
\hline Thibodeau (2018) & Yes & No & N/A \\
\hline Ulrich et al. (2015) & Yes & No & N/A \\
\hline $\begin{array}{l}\text { Van den Heuvel \& } \\
\text { Bondarouk (2017) }\end{array}$ & Yes & Yes & $\begin{array}{l}\text { The systematic identification and quantification of the } \\
\text { people drivers of business outcomes, with the purpose to } \\
\text { make better decisions (4) }\end{array}$ \\
\hline Walsh et al. (2010) & Yes & Yes & $\begin{array}{l}\text { Research-based approach [that] attempt[s] to understand } \\
\text { the effects caused by the implementation of HR programs } \\
\text { (14) }\end{array}$ \\
\hline Welbourne (2015) & Yes & Yes & $\begin{array}{l}\text { Compelling communication using data...to ensure that } \\
\text { critical insights are conveyed to the principal decision } \\
\text { makers in a way that maximizes the likelihood of taking } \\
\text { action (27) }\end{array}$ \\
\hline Witte (2016) & Yes & Yes & $\begin{array}{l}\text { The usage of data and data-based analysis as a basis for } \\
\text { decision making in companies and is currently a hot topic } \\
\text { in HR. }\end{array}$ \\
\hline
\end{tabular}


HR ANALYTICS AND STRATEGY

\section{HR Analytics and Employee Outcomes}

As described above, HR analytics has the potential to shape HR systems, policies, and practices, particularly when aligned with strategy, thereby shaping and affecting the way employees are treated at work. As such, HR analytics may be instrumental in shaping employee experiences and, more generally, affective, cognitive, behavioral outcomes at work and beyond. Over the years, a number of meta-analyses in the areas of industrial and organizational psychology and HR and organizational behavior have shown that indeed the application of statistical and data-analytic techniques commonly associated with HR analytics, such as regression, can demonstrate the effects of HR practices and interventions on employee outcomes.

As an example, a meta-analytic investigation of the effects work characteristics by Humphrey, Nahrgang, and Morgeson (2007) showed that employees' perception of autonomy at work tends to be associated with greater job satisfaction, objective performance, perceived meaning of work, and fewer absences. Further, the investigation showed that employees' perception of on-the-job feedback tends to be associated with greater job satisfaction, subjective ratings of performance, perceived meaning of work, as well as fewer absences. Given such findings, it stands to reason that improving employee perceptions of autonomy and on-the-job feedback using job (re)design and job crafting interventions can improve important employee outcomes, and the effectiveness of such interventions can be informed and evaluated as part of a HR analytics function. To that end, some scholars have proposed that redesigning jobs using lean production principles may improve employee outcomes, such as intrinsic motivation (De Treville \& Antonakis, 2006). In terms of empirical support, Campion and McClelland (1991) investigated the effects of a job design intervention aimed at increasing the number of tasks and 
HR ANALYTICS AND STRATEGY

responsibilities associated with a job, and they found that employees whose jobs were redesigned showed improved outcomes, such as higher employee satisfaction and customer services, but also higher training requirements. In sum, prior theory and empirical evidence has shown that indeed HR interventions can impact employee outcomes, and techniques and methodologies associated with HR analytics can be used to inform and support such interventions.

In addition, work by scholars and practitioners has suggested other direct linkages of HRrelated functions and employee outcomes. For example, Boselie et al. (2005) reported on empirical evidence supporting the intersection of human resource management (HRM) and performance, including employee satisfaction, motivation, retention, involvement, trust, loyalty and reduced absenteeism as outcomes of HRM activities. And Morgan (2017) strongly supported the intersection of experiential organizations, or companies that invest in improving employee experience shaped by culture, technology, and physical space, and employee outcomes. These results are reported as observed or anecdotal behavior including "a more productive workforce, a larger talent pipeline, improved levels of innovation, increased morale," improved customer service, brand value contributions and admiration and respect for the company (Morgan, 2017, p. 150). Additionally, high performance work practices contribute to improving employee experiences and is found to support bottom-line impact (Bates, 2001, 2003).

To that end, a company's business goals, successes, and failures can be directly attributed to the way people are treated in an organization (Bates, 2001; Davenport, Harris, \& Shapiro, 2007; Pfeffer \& Veiga, 1999). Furthermore, Boselie et al. (2005) recommends that HR focuses on "what drives people to generate business successes" (p. 3). At this point in time, scholars and practitioners can speculate that HR analytics has the potential to play a role in evaluating and 
HR ANALYTICS AND STRATEGY

implementing employee-experience strategies, and HR data can be collected, analyzed, and leveraged to justify employees' value and to provide evidence that they will produce quantifiable returns (Mondore et al., 2011).

\section{HR Analytics and Organizational Outcomes}

As noted in the introduction, there is a relative dearth of published, peer-reviewed evidence investigating the direct or causal impact of HR analytics on organizational outcomes (Angrave et al., 2016; Marler \& Boudreau, 2017; Mondore et al., 2011; Rasmussen \& Ulrich, 2014). Rasmussen and Ulrich referred to this phenomenon as "the lack of analytics on analytics" (p. 237). Of course, the absence of evidence on a particular phenomenon does not necessarily imply evidence of absence. Accordingly, more scholarly research is needed that explicitly investigates whether a well-defined and -integrated HR analytics function does indeed lead to improve organizational outcomes, such as firm performance, and under what conditions is this effect strongest or weakest.

In terms of non-peer-reviewed research, a recent Bersin report by Deloitte Consulting LLP (2017) found that organizations with a sophisticated HR analytics function reported " $82 \%$ higher three-year average profit" than low-maturity organizations. However, it remains inconclusive whether this is a direct, causal relationship, and scholarly research is needed to test this potential effect more rigorously. As another example of the promise of HR analytics when it comes to improving organizational outcomes, some have shown that when looking at large, publicly-traded companies, executive leaders often attribute the data-driven decisions made by its HR analytics team to business success, although such companies do not openly share the direct return on investment as a result of its people decisions (Davenport et al., 2007; Sullivan, 
HR ANALYTICS AND STRATEGY

2013). Some of the success stories associated with HR analytics, however, can best be described as anecdotal or perhaps company-specific. In sum, there remains a gap in the body of quantitative and qualitative scholarly evidence supporting the direct impact of HR analytics on bottom-line performance and return on investment (Marler \& Boudreau, 2017).

\section{Strategic HRM: State of the Science and Practice}

Given that HR analytics is being used as a foundation for organizational decision making in some companies, I contend that HR analytics can be used to support strategic HRM. In another sense, I argue that strategic HRM can serve as a foundation for understanding the importance of HR analytics and how it might inform and support HR and organizational strategy. Generally speaking, strategic HRM refers to situations in which HR initiatives "work in tandem" to support overall business strategy (Walsh et al., 2010, p. 8). The current body of literature suggests there are two key resources that contribute to supporting strategic HRM: people and systems. People refers to the employees in an organization who possess knowledge, skills, abilities, and motivation, and systems refers to the practices designed to further develop employees and their knowledge, skills, abilities, and motivation within an organization (Walsh et al., 2010). Further, strategic HRM is cross-functional in nature and involves multiple HR and business functions working in tandem and interdependently as a system (Jackson, Schuler, \& Jiang, 2014). There is some consensus regarding which common systems reinforce strategic HRM; these include resource orchestration, which encourages employee integration, and highperformance work practices, which focus on employee motivation and improvement of their knowledge, skills, and abilities (Alharthey \& Rasil, 2011; Combs et al. 2006; Taylor, Beechler, \& Napier, 1996). Overall, the main objectives of strategic HRM are to influence organizational 
HR ANALYTICS AND STRATEGY

decision making and determine how to leverage an organization's people as a competitive advantage (Alharthey \& Rasil, 2011; Combs et al. 2006; Taylor et al., 1996; Walsh et al., 2010).

\section{Defining Strategic HRM}

Strategic HRM can be broadly defined as the alignment of HR-related actions that are concerned with impacting overall business strategy and goals throughout an organization (Alharthey \& Rasli, 2011; Combs et al., 2006). Moreover, strategic HRM involves understanding how specific HR practices impact organization-wide initiatives and business outcomes (Combs et al., 2006; Huselid, 1995; Pfeffer \& Veiga, 1999). As mentioned previously, resource orchestration is a form of HR practice that supports strategic HRM as a whole. Resource orchestration suggests that it is the integration of "resources, capabilities and managerial acumen" from top-level to lower-level management that results in organizational success and ultimately a competitive advantage (Chadwick et al., 2015, p. 360). High performance work practices constitute a secondary approach to strategic HRM intended to enhance firm performance (Combs et al., 2006; Huselid, 1995). Examples of high performance work practices vary across organizations and include, but are not limited to, employment security, selective recruitment and hiring, self-managed teams, performance-based and incentive compensation, extensive training, transparency and information sharing, and flexible work arrangements (Combs et al., 2006; Huselid, 1995; Pfeffer \& Veiga, 1999).

HR analytics can be applied to identify and support high performance work practices in a particular company. For example, using HR analytics, Google created Project Oxygen with the overarching goal of categorizing the attributes of high-performing managers (Davenport et al., 2007). After conducting a series of interviews for both low- and high-performing managers, the 
HR ANALYTICS AND STRATEGY

company was able to pinpoint eight behavioral categories of good managers that could be used in future hiring and development of high-potential employees. In another example, the IBM Kenexa predictive hiring model illustrated how companies can use HR analytics to make data-driven decisions regarding candidates to eliminate the "guesswork" when recruiting for high-potential employees to join their workforce (Dorio, Rasch, \& Feinzig, 2014). As such, HR analytics can be used to measure and evaluate high performance work practices by leveraging data as opposed to anecdotal evidence or subjective judgments. In sum, strategic HRM can serve as the foundation for HR analytics, and similarly, HR analytics can be used to inform and support strategic HRM decision making, such as by identifying high performance work practices.

\section{Strategic HRM and Employee Outcomes}

When strategic HRM is realized across a whole organization, employees stand to benefit from it. Scholars recognize there to be multiple dimensions of strategic HRM practices that directly influence employee outcomes, including skill-, motivation-, and opportunity-enhancing practices (Combs et al., 2006; Jiang et al., 2012; Lepak et al., 2006). In turn, these practices influence employee outcomes such as knowledge, skills, abilities, and motivation. Namely, in their meta-analytic investigation of 120 studies, Jiang, Lepak, Hu, \& Baer (2012) found that skill-enhancing practices (e.g., recruitment, selection, training) exhibited stronger, positive relations with the quality of human resources in an organization, which includes employees' knowledge, skills, and abilities. In contrast, motivation-enhancing practices (e.g., performance management, compensation, benefits, job security) and opportunity-enhancing practices (e.g., job design, teamwork) showed stronger relations with employee motivation. Building employees' knowledge, skills, abilities, and motivation can have direct benefits for the 
HR ANALYTICS AND STRATEGY

employees themselves, as doing so may help employees reap the benefits of a pay-forperformance system (should one be in place) by performing at a higher level, and more generally, improve their employability and promotability. As I will describe in the following section, collectively, the employee outcomes of knowledge, skills, abilities, and motivation have important implications for organizational outcomes.

\section{Strategic HRM and Organizational Outcomes}

In addition to employee impact, strategic HRM practices have demonstrated effects on organizational outcomes. For instance, in the same aforementioned meta-analytic investigation by Jiang et al. (2012), skill-, -motivation, and -opportunity-enhancing practices were shown to ultimately lead to better organizational outcomes, including lower turnover, higher productivity, and better financial outcomes (e.g., return on assets, sales growth) via the employee outcomes of knowledge, skills, abilities, and motivation. In other words, strategic HRM practices have the potential to improve employees' knowledge, skills, abilities, and motivation, and these human resources (collectively known as human capital) can, in turn, lead to organizational performance (Combs et al., 2006; Jiang et al., 2012). Further, numerous proponents of high performance work practices, as derived from commitment-based HR systems, have reported positive results on organizational performance, including "lower turnover, higher employee productivity, and superior financial and stock market results" (Chadwick et al., 2015, p. 364). Whole Foods Market, for example, attributed its significant sales growth (864\%) and net income growth (438\%) between 1991 and 1996 to its team-oriented philosophy and management practices, including self-managing teams and information sharing (Pfeffer \& Veiga, 1999), which presumably impacted employees' knowledge, skills, abilities, and motivation, and ultimately the 
HR ANALYTICS AND STRATEGY

financial outcomes. In a study conducted on 190 multi-industry Korean firms, Chadwick et al. (2015) found an average increase in sales per employee of $\$ 129,527$ per a one-unit increase in commitment-based HR systems. This not only demonstrates its potential impact on employee performance but implies positive results on firm performance as well. Additionally, numerous studies have demonstrated that a single standard deviation increase in high performance work practices has potential to lead to significant economic returns, including $\$ 27,044$ more in sales per employee and up to $\$ 41,000$ of shareholder value per employee (Pfeffer \& Veiga, 1999). However, it is important to consider that these outcomes vary depending on the type of organization; for example, multinational corporations and international business provide different contexts for the organizational impact of strategic HRM (Taylor et al., 1996). In sum, accumulated evidence has shown that HR practices consistent with strategic HRM philosophies tend to lead to better organizational outcomes, and it can be argued that HR analytics can be used to inform and support strategic HRM by collecting and analyzing data related to such practices and systems associated with strategic HRM.

\section{Developing a HR Analytics Function}

Considering the positive implications of strategic HRM and HR analytics in the literature, there are also challenges involved with developing and designing a HR analytics function. And issues pertaining to design and development may have direct implications for the success of a HR analytics function. As Jackson et al. (2014) noted, traditional HRM can be characterized by designing policies and practices that align with business goals after the fact of them being created; however, the modern role of HR professionals is shifting to one that is actively involved in the decision-making process for business planning and strategy. The first challenge of the 
HR ANALYTICS AND STRATEGY

design and development phase involves building organizational support for HR analytics. This is a critical step because when key stakeholders understand the value and involvement required for an effective HR analytics function, future barriers to implementation are likely to be eliminated or mitigated earlier in the process.

\section{Building Organizational Support for HR Analytics}

Despite HR analytics being associated with successful companies such as Google, Apple, Disney, Amazon and Microsoft (Bock, 2015; Boudreau \& Ramstad, 2007; Morgan, 2017), some companies have been reluctant to design and develop a HR analytics function (Bassi, 2011; Falleta, 2014; Rasmussen \& Ulrich, 2014). Building the necessary support from upper management and decision makers to support a HR analytics initiative will be the first challenge HR leaders may face prior to implementing a robust analytics function (Rasmussen \& Ulrich, 2015). HR leaders should acknowledge any barriers, such as cost, time, capability and bandwidth, the company may face when implementing, but also be able to demonstrate how a properly designed function will outweigh the costs and result in improved firm performance (Deloitte's Bersin Finds Effective Use of People Analytics Is Strongly Related to Improved Talent and Business Outcomes, 2017).

In many cases, companies leverage HR analytics as an opportunity to reduce hiring costs and attrition via quantifiable methods (Harris \& Light, 2011). For example, the IBM people analytics team developed an algorithm that allows managers to "deliver personalized coaching and guidance" tailored towards individual employees; as a result, they were reportedly able to reduce employee attrition by $2 \%$ (Morgan, 2017, p. 40). The analytics team also developed a program called "Blue Matching" designed to connect current employees with job opportunities 
HR ANALYTICS AND STRATEGY

within the company, thereby aligning their "skills, performance, location and area of expertise" (Morgan, 2017, p. 40). Since implementing Blue Matching, the company successfully completed 500 job placements for employees who otherwise could have left IBM to seek opportunities elsewhere. The case of IBM is just one case of a company that was able to significantly reduce and prevent attrition by leveraging HR analytics.

If HR leaders are able to gain buy-in from executive leaders and convince them to invest in HR analytics, the function is more likely to gain sufficient funding for the resources needed to implement a successful analytics function (Hunt, 2014). One way to encourage buy-in from managers is incorporating compelling data and information and data visualizations that aid in understanding the impact of HR analytics on firm performance (McAfee \& Brynjolfsson, 2012). For example, the performance yield curve is a well-known visual aid for understanding the impact of business operations and management practices on strategic value and performance in an organization (Boudreau \& Ramstad, 2007; Cascio \& Boudreau, 2011). The conceptual graph depicted in Figure 3 illustrates how small changes in management practices have the potential to make a tremendous difference on strategy realization and value in an organization. The top curve can represent a resource that often maintains an incremental impact on firm performance, but once that resource is slowly removed from the organization it would reach a "pivot point" in which its performance impact would drop drastically (Boudreau \& Ramstad, 2007). The bottom curve can represent a resource that holds average value on firm performance except that a small change would not result in a significant reduction on firm performance (Boudreau \& Ramstad, 2007). 
HR ANALYTICS AND STRATEGY

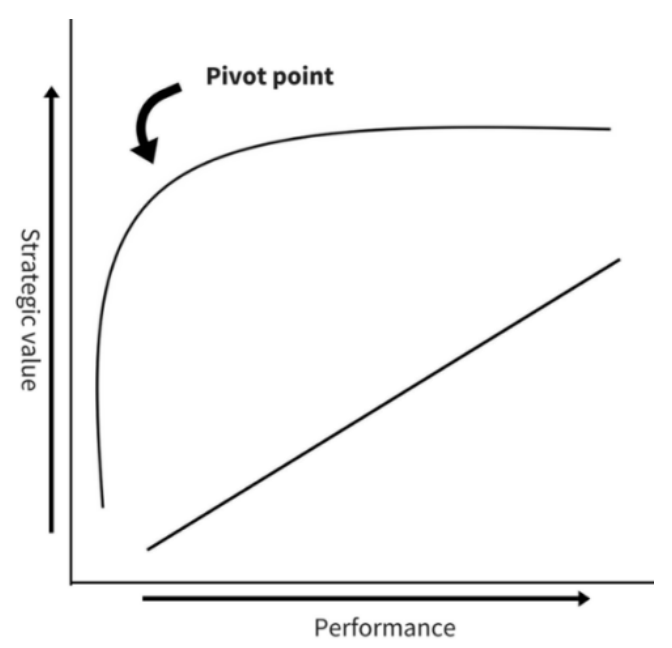

Figure 3. This graph illustrates a performance yield curve, and how certain management practices impact a firm's strategic value and performance (adapted from Boudreau \& Ramstad, 2007).

To illustrate this model in action, consider the performance of Disney employees and their impact on guest satisfaction at its theme park attractions; an employee in the Mickey Mouse costume can be represented by the top curve and "sweepers," or park employees responsible for guiding and answering guest questions, are represented by the bottom curve (Cascio \& Boudreau, 2011) (see Figure 4). Because the Mickey Mouse character is incrementally valued by park guests, Disney has eliminated room for error in this role by protecting the identity of the person in costume, not allowing the character to speak, and accompanying the character with a supervisor to manage guest interactions (Cascio \& Boudreau, 2011). As a result, talent of the Mickey Mouse character is likely to remain consistent and plateau on the top performance curve, whereas park sweepers have greater freedom to customize guest interactions resulting in more variation in performance below the curve. With this example aside, HR leaders can use the 
HR ANALYTICS AND STRATEGY

performance yield curve as a tool to demonstrate how changes in an organization can be critical for firm performance. In sum, high performance work practices, for instance, may not be essential in all cases for a business to operate, but if deployed successfully they could result in significant value to the organization.

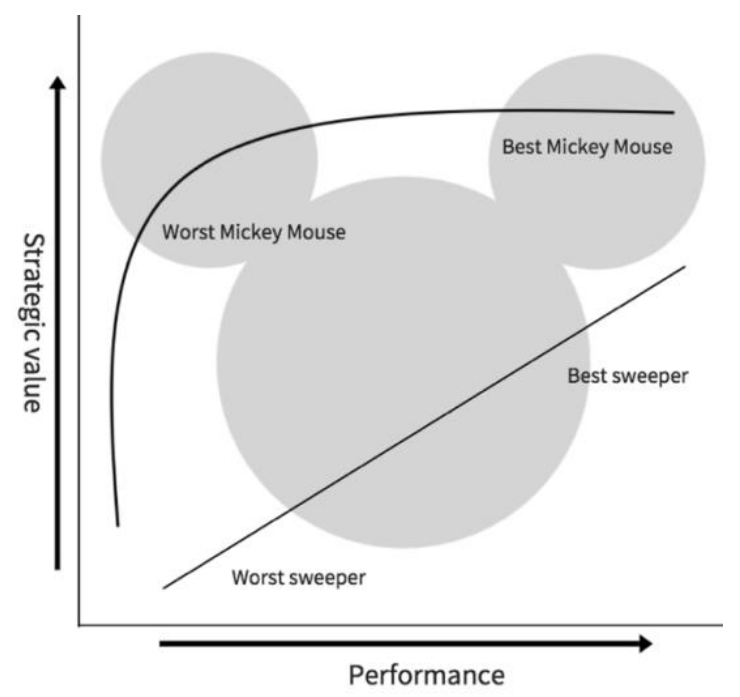

Figure 4. This graph illustrates Disneyland's Mickey Mouse versus Sweeper performance and contextualizes the performance yield curve with the case of Disney employees or "cast members" (adapted from Cascio \& Boudreau, 2011).

Moreover, data-driven storytelling is another method for gaining organizational support (Welbourne, 2015). This is a practice that extends beyond the human resources function to other cross-functional departments (Welbourne, 2015). When HR professionals take the next step to influence buy-in from the leadership team, they must be able to link data information with actionable outcomes in order to address relevant business challenges (Isson \& Harriot, 2012). While colorful and well-designed charts and graphs may aid in the visual appeal of a data 
HR ANALYTICS AND STRATEGY

presentation, HR leaders that are able to articulate a compelling story that evokes emotion are likely to generate action from senior leadership (Welbourne, 2015). This could be achieved by "branding" HR analytics as an incrementally valuable resource in supporting management and employee objectives (Hunt, 2014). HR leaders might consider partnering with their marketing department to create a branded story and tell a data-driven narrative for building organizational support. HR leaders might also consider adapting the following three frameworks when presenting the possibility of how a HR analytics function may work for their organization: Capability-Opportunity-Motivation (COM) model, Logical, Analytics, Measures, and Process (LAMP) framework, and Business Analytics Success Pillars (BASP) framework.

Capability-Opportunity-Motivation (COM) model. Levenson (2010) recommends the Capability-Opportunity-Motivation (COM) model as a stepping stone for HR analytics that does not require the application of advanced statistical and data-analytic techniques. The purpose of the COM model is to enable managers, who may not necessarily have the bandwidth to conduct in-depth analytics, to ask the right diagnostic questions and test scenarios to better understand the behavior, motivation, and performance of their employees. According to this model, capability represents the time spent on training and development for an employee to achieve full productivity in a new role. Next, opportunity refers to both formal and informal processes that enable or hinder employee performance. Finally, motivation refers to the consideration of all factors that may affect an employee's ability to stay motivated (i.e., supervisors, co-workers, work-life balance, compensation and rewards). Rather than conducting in-depth data analytics, using this model, one can leverage simple survey methods to identify the range of data that should be collected in order to establish a foundation for further analysis. Although this 
HR ANALYTICS AND STRATEGY

framework does not involve heavy analytics, each factors of COM have been shown to be indicators of employee motivation and performance. Overall, the COM model strives to enhance an organization's productivity, and the concepts of capability, opportunity, and motivation generally map onto skill-, opportunity-, and motivation-enhancing strategic HRM practices, respectively, which were discussed earlier in this review and which have received a great deal of attention in the strategic HRM literature.

Starbucks is an example of a company that utilizes the COM model to realize enhanced performance throughout more than 11,000 stores worldwide. Dave Pace, executive vice president of Partner Resources at Starbucks, attributed the reason for its business success to the way employees are treated (Boudreau \& Ramstad, 2007). Pace believed its rapid growth model and storewide success was a result of its embedded culture of trust within the organization. The capabilities aspect of Starbucks' talent practices begins with extensive training and development. Before a new employee or "partner" is allowed to begin hands-on training, they undergo extensive learning on its product portfolio with six hours to complete all sections of the training material. Each section is designed to emphasize the responsibilities of a Starbucks barista, expected levels of service, and is followed by a written test. Store managers further develop employees by encouraging them to customize the way they deliver the Starbucks experience by incorporating their unique talents and capabilities so long as the quality of service remains consistent.

Starbucks also creates opportunities wherein employees may apply their capabilities. Although there are a number of formal processes in place at every store, there are certain informal processes that enable baristas to excel in their performance. For example, one Starbucks 
HR ANALYTICS AND STRATEGY

barista in Cincinnati, Ohio noticed that yelling orders began to strain her voice. As a trained opera singer, she approached her manager and asked if she could sing the orders instead. Consequently, she was able to not only save her voice but deliver a new form of charm to her store and create a unique experience for customers. Furthermore, baristas are encouraged to “experiment and produce new product ideas" (Boudreau \& Ramstad, 2007, p.162).

In addition to the customizable in-store experience at Starbucks, other factors that contribute to the motivation of employees include health insurance for all frontline staff and similar pay and benefits regardless of a barista's part- or full-time employment status. The case of Starbucks' people practices sheds light on how a company is able to experience rapid growth and financial success by implementing employee retention tactics and striving for consistent customer satisfaction. It is important to note that advanced HR analytics was not used in this case, but that the COM model was used to strive for organizational success. When it comes to recruiting partners, who are fluent in data analysis, Starbucks' director of market planning, Patrick O'Hagan, seeks people with proficiency in a variety of statistical programs such as " $\mathrm{R}$, Python, and Tableau" (Khoso, 2016). However, the details as to how Starbucks applies HR analytics to its people practices is not apparent in the information pertaining to this specific case involving the COM model.

Logical, Analytics, Measures, and Process (LAMP) framework. Cascio and Boudreau (2011) introduce Logistics, Analytics, Measures, and Process (LAMP) framework to help business leaders to conceptualize how HR analytics will be designed as well as to identify important factors to emphasize to management. First, the term logical emphasizes the importance of drawing logical connections to explain data that are collected, their effects on the business and 
HR ANALYTICS AND STRATEGY

any plausible outcomes. Second, the term analytics refers to the importance that data are analyzed and interpreted correctly to avoid incorrect assumptions. Third, the term measures encourages managers to focus on the quality of data, not quantity, and its potential to drive organizational impact. Finally, the term process refers to the change-management process that must occur once management accepts that $\mathrm{HR}$ analytics will be valuable and informative to their organization. They recommend that HR leaders align their analytics initiative with existing problems and discussions the organization is currently facing. This way, HR leaders may gain credibility quickly and become actively involved in conversation at the leadership table (Cascio \& Boudreau, 2011). Together, the components of the LAMP framework offer a way to ensure that a relevant and strategically-aligned HR analytics function is designed and developed.

Business Analytics Success Pillars (BASP) framework. Developed by Isson and Harriot (2012), the Business Analytics Success Pillars (BASP) framework serves as a tool for managers to mobilize through the five stages of analytical maturity (Davenport et al., 2007), with the ultimate goal of achieving a competitive advantage in business analytics. BASP is founded upon seven pillars that can be used as a guide to strategically align a HR analytics function with a company's overarching business objectives; these pillars include: business challenges, data foundation, analytics implementation, insight, execution and measurement, distributed knowledge, and innovation. As there is never a one-size-fits-all strategy (Bassi, 2011; Bates, 2003), there is no chronological order that leaders must follow when using BASP; instead the seven pillars should align with the company's mission, core values, and strategy.

Three of the seven pillars are particularly relevant during the design and development process. The first is the business challenges pillar, which translates to planning for an analytics 
HR ANALYTICS AND STRATEGY

function that is driven by critical business challenges, thereby resulting in increased profitability or decreasing costs. Designing an analytics function around critical challenges will focus management on pressing business needs rather than the individual curiosity of management. The second pillar is data foundation, which urges an organization to consider how and what type of data it will collect for subsequent analysis. It is recommended that an organization conducts a data audit in which a team or individual searches for all internal sources of data outside the HR department, collects external data that provides insight about the market and competitors, prioritizes data that aligns with critical business challenges, and creates a customer data profile that is stored in one place. This pillar will also enable managers to sort through and discard unnecessary data. Finally, once management has agreed on the desired business outcomes of their HR analytics function, the analytics implementation pillar serves to remind business leaders to implement data analytics with the end-users in mind and anticipate their actions as a result of the initiative. It is important for management to also consider how employees might respond to HR analytics when addressing new challenges and business problems.

\section{Resource Orchestration}

A secondary aspect of developing and design of a HR analytics function is concerned with planning how the organization will ultimately communicate and share resources crossfunctionally during the implementation phase. This is made possible when individuals collaborate and work in cohesion within an organization to achieve competitive advantage (Alharthey \& Rasli, 2011; Beatty, 2005; Bassi, 2011).

When it comes to resource orchestration in action, consider the case of Restaurant.com, a business-to-business and business-to-consumer web-based organization that recognizes the 
HR ANALYTICS AND STRATEGY

importance of sharing data-analytics resources across the entire organization (Isson \& Harriott, 2012). Restaurant.com houses a centralized analytics function that ensures individual departments that choose to use analytics interpret results in alignment with and with consideration of the data from other areas of the organization (Isson \& Harriott, 2012). Restaurant.com President and Chief Marketing Officer, Christopher Kohn, recommended that each department generates reports based on the same data source to ensure consensus on the “tools, sources and data definitions" used across the organization (Isson \& Harriott, 2012, p.40). Through its consistent expectations and shared resources, this company demonstrates resources orchestration in its data analytics practice. This practice of resources orchestration is important because it allows the company to build predictive models that align with other departments and forecast the return on investment of its analytics initiatives (Isson \& Harriott, 2012). The limitation of this particular case study is that it does not provide concrete examples of the direct impact resource orchestration has on HR analytics, specifically. Nonetheless, general dataanalytics best practices can be gleaned from the case of Restaurant.com.

\section{Summary}

When it comes to the development and design of a HR analytics function, there are many factors to consider prior to implementation including building organizational support from key stakeholders and planning the integration of resources to streamline the process. For example, the performance yield curve and COM, LAMP, and BASP frameworks can be leveraged to overcome the challenge of convincing executive management to support HR analytics. Lastly, HR leaders should emphasize clear communication across departments and functions so that all areas of the business are able to benefit from the initiative. 
HR ANALYTICS AND STRATEGY

\section{Implementing a HR Analytics Function}

The next major phase of deploying a HR analytics function is implementation, which should involve an effective change management strategy, appropriate resource allocation, and meticulous evaluation of the results. Ultimately, effective HR analytics implementation requires careful incorporation and integration of HR analytics into HR systems as well as into the broader organizational system. There are a number of approaches management can take to incorporate and integrate HR analytics into its HR and organizational practices and systems. Some companies choose to conduct analytics within the HR department (Morgan, 2017), some integrate their analytics with the organization's information technology function (Barton \& Court, 2012; Bates, 2003), and others opt for a separate cross-functional analytics department (Isson \& Harriott, 2012). Brown (2013) recommends that implementing some form of HR analytics in a company will be valuable for organizations with over 100 employees that spend at least $25 \%$ of its costs on total compensation. In the following section, I describe the importance of organizational change management, resource allocation, and evaluation of results.

\section{Organizational Change Management}

The underlying purpose for introducing an HR analytics function should be to drive organizational change through enhanced decision making (Cascio \& Boudreau, 2011), but at the same time, the implementation of a HR analytics function requires its own change-management process. During the implementation phase, HR professionals have the opportunity to play a critical role in communicating and engaging employees through the major anticipated or forthcoming changes. An effective change-management process is essential for a smoother transition for stakeholders involved in the process. For instance, Hunt (2014) asserts the 
HR ANALYTICS AND STRATEGY

importance of being "extremely clear about what you are changing, why you are changing it, and how it will benefit the people affected by the change" when initiating a change management process (p.335). Further, Hunt contends that HR leaders should also act as support agents for everyone involved and provide the necessary training and tools to support the change.

Barrette (2015) introduced two major aspects of change management that can help HR leaders be successful: "listening and learning," and "consulting and strategy building" (p. 14). The listening and learning phase involves engaging with employees, one-on-one or in a group setting, to facilitate conversations surrounding their most pressing business needs. Additionally, the consulting and strategy building phase comes in to play when HR leaders take into account the feedback received and act as a strategic advisor to justify the rationale, make predictions, and recommend action regarding data analyses. All the while, HR should anticipate potential pushback from upper management in terms of HR analytics initiatives and strive to quickly address unexpected outcomes that may arise (Bates, 2003). As soon as business leaders realize their analytics function is not delivering the desired results, they should work on realigning HR analytic practices to meet anticipated business outcomes. That is, a HR analytics function should target solving important problems and answering important questions that are of interest to key stakeholders. Moreover, the change-management process can be viewed as a feedback-iteration cycle as management priorities and business conditions are constantly changing (Barrette, 2015). In other words, change management involves more than just data collection, analysis, and interpretation; namely, it requires human touch, transparency with employees, and open communication. 
HR ANALYTICS AND STRATEGY

\section{Resource Allocation}

As part of the implementation process, business leaders must allocate resources based on the needs of the organization and key stakeholders. So what exactly is required for successfully deploying HR analytics in an organization? In the following sections, I consider the following four requirements for HR analytics implementation: analytic competencies, cost, time and space, and data sharing.

Analytics competencies. In terms of the required competencies for conducting and interpreting HR analytics, this continues to be a debate amongst the literature (Edwards \& Edwards, 2016; Lawler, Levenson \& Boudreau, 2004; Levenson, 2010). Generally speaking, business leaders fear that society is facing a skills gap and a talent shortage (Morgan, 2017). This concern may be associated with an organization's fear that it lacks the bandwidth or the necessary talent, in terms of knowledge, skills, abilities, and motivation, to successfully implement HR analytics (Barton \& Court, 2012). Some companies believe that their existing employees need to "develop more skills and capabilities in the area of HR analytics" (Witte, 2016, p. 28), whereas alternatively one might argue that such skills and capabilities might be acquired via recruitment and selection processes.

Regardless of how a company generates analytics competencies among its workforce, a talent shortage may nonetheless be on the horizon. Research conducted by the McKinsey Global Institute found that advanced economies could be facing up to 95 million workers that lack the skills employers need (Dobbs, Madgavkar, Barton, Labaye, Manyika, Roxburgh, Lund \& Madhav, 2012). The University of Michigan's Ross School of Business researched HR competencies over a 10-year span (1988 to 1998) and revealed a pivotal shift in HR 
HR ANALYTICS AND STRATEGY

professionals spending less time on administrative processes and more time on key strategic issues - in other words, moving from transactional activities to more transformational activities (Becker, Huselid, \& Ulrich, 2001). One finding suggested that HR professionals are expected to be knowledgeable about "financial management and external competitive and customer demands" and to demonstrate the ability to clearly communicate the goals and future directions of the firm (Becker et al., 2001, p. 158). The talent shortage continues to be a challenge for recruiters as there is a scarce number of university programs that graduate undergraduate students in preparation for HR analytics (see Bauer \& Caughlin, 2017; Davenport \& Patil, 2012).

Cost. One of the biggest questions management is concerned about with HR analytics initiatives is its cost (Carlson \& Kavanaugh, 2015) and return on investment (Barton \& Court, 2012). Traditional HR administrative costs, however, typically comprise of a slim $3 \%$ of selling, general, and administrative (SG\&A) expenses on a company's balance sheet (Harris \& Light, 2011). Organizations should have a plan in place for measuring the effects on employee and firm performance as a result of additional costs required to conduct effective HR analytics (e.g., software and technology, selecting and training employees). While it is known amongst scholars that HR analytics has the potential to play an important role in value creation (Boudreau \& Ramstad, 2007; Fitz-enz, 2010), implementation can take years due to inadequate resource allocation and funding (Fitz-enz, 2010). This is especially evident when the leadership team does not fully support and understand the strategic value HR analytics might bring to the organization.

When addressing cost, HR leaders might consider sharing success stories and anecdotes from other companies that have implemented a HR analytics function and realized significant cost savings as a result. For example, SYSCO Corporation, a global leader in food-service 
HR ANALYTICS AND STRATEGY

marketing and distribution, measured three key HR metrics including "work climate and employee satisfaction, productivity (measured as employees per 100,000 cases of food sold), and retention" (Harris \& Light, 2011, p. 8). Upon analysis of these key metrics, the company discovered that internal stakeholders with high employee satisfaction experienced higher revenue, lower costs, superior customer loyalty and better retention rates (Harris \& Light, 2011). Consequently, SYSCO chose to measure seven dimensions of its work environment with the goal of managing employee satisfaction. Not only did SYSCO develop a database for stakeholders to access best practices, but it was able to identify underperforming units and seek to improve those areas accordingly, all while using HR analytics to support decision making. As a result, SYSCO improved its retention rate for delivery associates by $20 \%$ in a six-year span and saved nearly \$50 million in hiring and training costs (Harris \& Light, 2011). Ultimately, the biggest expense to implementing HR analytics is not the actual cost of collecting HR data but the time needed for designing the function (Brown, 2013).

Time and space. The ability for managers and employees to give the HR department the time and space needed to conduct actionable analysis is another concern companies may have around the idea of deploying a HR analytics function (Edwards \& Edwards, 2016). For example, in most developed HR analytics teams, there are seven major steps that must take place before drawing strategic conclusions, which include but are not limited to (a) understanding the data available, (b) asking the right questions, (c) testing and exploring analytic models, (d) running the analysis, (e) questioning the analysis, (f) re-running the analysis, and (g) further interrogating the results (Edwards \& Edwards, 2016). 
HR ANALYTICS AND STRATEGY

To address the time and space concerns, companies may consider re-designing their HR department to reflect the time and space needed to perform a robust analytics function. For example, they may separate administrative HR tasks from strategic HR tasks. Whereas administrative HR involves functional tasks such as payroll processing, administering medical benefits, handling contract work related to hiring, and terminating employees, strategic HR includes tasks aimed at gaining a competitive advantage, increasing workforce productivity, and impacting "profit, growth, and long-term sustainability" in an organization (Hunt, 2014, p.3). Hunt argues that it is through strategic HR tasks that a HR department can add value, which can be informed and evaluated by using HR analytics. It is fair to reason that an organization might assign HR professionals who specialize in one or the other, so that their time is not spread too thin tackling both administrative and strategic functions. For example, IBM has a HR analytics team that is distinct from its administrative HR department, the former of which has grown to over 70 employees (Morgan, 2017).

Ultimately, the need for time and space in deploying a HR analytics function should strive to reduce time spent on unnecessary HR tasks that otherwise would not be identified without a HR analytics function. Google serves as an example of how a company was able to reduce time spent on interviewing. Google's People Analytics team analyzed high performers within the organization to determine the backgrounds and capabilities associated with those employees (Davenport et al., 2007). This allowed hiring managers to significantly streamline its interview process to five interviews rather than 10 (Davenport et al., 2007). In this example, Google's analytics team was provided with the time and space to conduct its HR analytics, and in doing so, cut time spent on interviewing in half for the company. 
HR ANALYTICS AND STRATEGY

Data sharing. In a survey conducted by the Columbia Business School's Center on Global Brand Leadership and the New York American Marketing Association (NYAMA), 51\% of the companies surveyed claimed their biggest barrier to big data implementation was the "lack of sharing of data among company departments" (Isson \& Harriot, 2012, p.68). One of the pillars in the BASP framework suggests that "distributed knowledge," is an essential factor in an analytics function" (Isson \& Harriot, 2012). Isson and Harriot argue that rather than a “command-and-control" management approach for distributing analytics knowledge, a competitive analytics function should strategize a collective approach to sharing information; this way, data analytics is accessible to all critical stakeholders and value is realized across the entire organization (p. 44-45). Companies who are unable to integrate and leverage data effectively for strategic HRM will continue to be at a disadvantage when compared to companies that succeed in this regard (Hunt, 2014; Isson \& Harriot, 2012).

Another way companies can leverage effective data sharing is through investment in appropriate information systems and technology (Carlson \& Kavanaugh, 2015). In recent years, many companies have transitioned from operating and maintaining their own data servers to contracting with another firm that hosts their data via cloud-based human resource information systems (HRISs), and now more than $60 \%$ of companies use mobile-based technology to implement HR tasks (Gale, 2015). Organizations should choose a cloud-based or electronic software platform where all HR data can live digitally (Barton \& Court, 2012). As Hunt (2014) notes, if a company has not already made the transition from paper to digital files, then it should digitize its data in order to build an effective HR analytics function, and moreover, when selecting the appropriate HR information system to deploy, managers should consider the 
HR ANALYTICS AND STRATEGY

functionality, usability, accessibility, and transparency the technology will provide. The selected technology should be accessible and usable to minimize barriers for logging into the system and managers should consider the learning curve required to navigate through the system (Hunt, 2014).

\section{Evaluation}

A thorough evaluation of business performance and results is a final and critical aspect of implementing an effective HR analytics function. According to an article published by the firm Deloitte (Deloitte's Bersin Finds Effective Use of People Analytics Is Strongly Related to Improved Talent and Business Outcomes, 2017), the last stage in achieving analytic maturity is when "data-driven decision-making is embedded in the culture." This requires continuous follow-up and evaluation on the impact HR analytic initiatives have on daily decision making by executive leaders in an organization. Referring back to the BASP framework, the previously undiscussed execution and measurement pillar encourages management to integrate solutions and take action derived from data insights and implementation. Analytic solutions should also be utilized by internal stakeholders to generate positive change and support the organization's desired business outcomes. Measurement should be a constant practice during the evaluation phase to track stakeholder adoption, bottom-line impact, and other metrics linking execution with results (Isson \& Harriot, 2012). Finally, the innovation pillar from the BASP framework serves to remind managers that business and technology are dynamic fields in which analytics must adapt accordingly in order to remain agile and competitive (Isson \& Harriot, 2012).

Furthermore, it is important to recognize that a continuous learning curve is critical following the initial implementation step. Managers should continue to seek external academic 
HR ANALYTICS AND STRATEGY

published research, HR analytic outcomes from benchmark organizations, and their company's own internal HR analytics findings to support future change and progression in their HR analytics practices. The evaluation phase might consider integrating organizational research to account for other factors related to measuring the impact of HR initiatives on performance. According to Kaur and Fink (2017), organizational research encourages HR professionals to evaluate workforce performance not only within their company but also outside of the company. External research can help business leaders gain insight beyond the internal organization and prescribe action accordingly. For example, Google's People Analytics function includes a team of 30 researchers, analysts, and consultants dedicated to researching employee-related decisions and issues (Davenport et al., 2007). Considering that today's business climate is constantly evolving, it is critical for management to proactively study organizational issues beyond the company to aid in evaluation and decision-making processes.

\section{HR Analytics Successes}

Given the recommended processes involved in designing, developing, and implementing HR analytics, case studies that demonstrate HR analytics successes can elucidate important contextual details that bring concepts and techniques to life and showcase how HR analytics can be leveraged to inform and support strategy. In the following sections, I present cases studies on Jack in the Box, Convergys, AC Milan, and Chevron. Jack in the Box introduces a restaurant industry concept known as the service-profit chain for analytics achievement in the areas of productivity, customer satisfaction, and reduced attrition. Convergys created an integrated marketing and HR analytics function to provide employees with custom benefits aimed at reducing attrition. AC Milan houses an analytics lab to predict and select high-performing 
HR ANALYTICS AND STRATEGY

players and customize training programs that support player longevity. Finally, Chevron demonstrates its ability to leverage HR analytics to predict attrition by location while developing analytic teams across the organization.

\section{The Case of Jack in the Box}

The restaurant industry has several notable examples of businesses that incorporate strategy and analytics into their HR practices and systems (Heskett, Jones, Loveman, Sasser, \& Schlesinger, 2008; Isson \& Harriott, 2012). In Schiemann and Seibert's (2017) practice forum, Jack in the Box's Chief of People, Mark Blankenship, shared how the company began utilizing the service-profit chain ${ }^{1}$ and People Equity Model to measure its people investments as effective predictors of business outcomes. The People Equity Model includes three factors - Alignment, Capabilities, and Engagement - otherwise known as the ACE Scorecard. The scorecard can be summarized as the degree to which (a) employees are aligned with the company's brand, goals, and customer service; (b) employee capabilities meet or exceed the needs of both internal and external stakeholders; and (c) employees show engagement with regards to "satisfaction, commitment and advocacy" (p. 318). Data were collected in the form of employee surveys, and data were analyzed using regression analysis to understand the relative impact of ACE results as predictors of business performance.

The ACE scorecard enabled managers to find that restaurants with higher ACE scores actually outperformed those with lower scores, both operationally and financially. Management

\footnotetext{
${ }^{1}$ Service-profit chain is the linkage between customer loyalty and profitability and growth as a result of employee satisfaction in the service industry (Heskett et al., 2008).
} 
HR ANALYTICS AND STRATEGY

was not only able to pinpoint underperforming restaurants, but specifically were able to identify that a lack of employee capabilities was the most significant predictor of employee attrition and guest dissatisfaction. Consequently, Jack in the Box prescribed action based on these findings to train restaurant managers on the importance of training capabilities with their employees. Furthermore, Jack in the Box customized their analytics approach by aligning it with their culture of "head, heart and hands" to ensure that employees were aligned with its core values and managers understand how it plays a role in decision-making. As a result of restaurant optimization by the ACE scorecard, Jack in the Box experienced 21\% less attrition (\$27,000 less costs) and 10\% higher productivity ( $\$ 72,000$ increased profits) per restaurant per year; Blankenship equates this impact to be in the millions of dollars when multiplied across all Jack in the Box locations. Jack in the Box's use of HR analytics exemplifies three aspects of its impact on firm performance: reduced attrition, improved productivity, and improved customer satisfaction.

\section{The Case of Convergys}

Harris and Light (2011) shared how Convergys, a HR service agency specializing in compensation and benefits administration, utilized analytics to "calculate what employees value most" and generated a plan to reduce turnover within the company (p. 8). Since its initial public offering, employee attrition was the company's biggest employee issue. In response, the company adapted a "consumer marketing technique, conjoint analysis" to predict employee preferences and future behavior in the workplace, and tailored HR actions accordingly in efforts to support retention (p. 8). Consequently, managers were able to determine customized benefits plans for its employees by region. This analytic technique followed by predictive modeling and 
HR ANALYTICS AND STRATEGY

action mirrors what other large companies such as Google and Facebook are doing to support their unique assortments of employee benefits (Smith, 2016; Sullivan, 2013). Despite being a considerable investment, the custom benefits adjustments were made possible at a low-cost to the company. As a result, Convergys estimated its attrition was reduced by 58,000 over four years and saved $\$ 57$ million on recruiting and training costs. This is one example of a company that calculated significant cost savings and reduced attrition as a result of action prescribed by HR analytics.

\section{The Case of A.C. Milan}

Harris and Light (2011) also presented the case of AC Milan, a professional Italian soccer team that reportedly used data analytics to predict high performance and longevity of its players. The purpose of longevity (or durability) of recruiting players was to determine who was the healthiest and least susceptible to injury, thereby demonstrating greater value over a long period of time to the team. (From a HR perspective, player longevity can be compared to employee turnover.) To do this, AC Milan constructed a research lab that collects up to 60,000 data points on each of its players, examining both physical and psychological traits. By implementing extensive data analyses, the team was able to leverage data to determine players that are more likely to yield consistent high performance. In terms of injury-prevention, AC Milan frequently tests players to identify the development of habits that could lead to future injury. Jeanne-Pierre Meersseman, lab director, explained they use predictive algorithms and fact-based assessments to customize training regimes designed for maximizing player longevity. As a result, AC Milan was able to reduce injuries by over $90 \%$ in a five-year span. Although this case is often categorized as sports analytics, it is arguably a form of HR analytics in that it suggests an 
HR ANALYTICS AND STRATEGY

organization with the proper resources has potential to formulate a data-driven method for retaining and developing key talent (longevity and injury-prevention, in this case) thereby reducing turnover, or attrition.

\section{The Case of Chevron}

As a multinational leader in energy and oil, Chevron faced the challenge of maximizing its profits and revenue per employee given the economy of falling oil prices (Collins, Fineman, \& Tsuchida, 2017). In response, Chevron's Head of Talent Analytics, RJ Minor, articulated the importance of "informing and supporting business strategy" through people and HR data to solve critical business problems and to provide unique insight (How Data Shapes Talent Strategy, 2017). Minor shared that one of the biggest challenges in talent analytics is determining the most important metrics HR should measure which he recommends should be based on business strategy. In support of this recommendation, Chevron reinvented its traditional HR analytics model that was previously conducting standard reporting to one in which HR analytics teams operated across departments trained by an "in-house analytics curriculum" (Collins et al., 2017; McKeon, n.d.). As a result of this organization-wide shift, Chevron's improved analytic model achieved $30 \%$ higher productivity while operating at a significantly lower cost and was able to accomplish more with fewer people and in less time (Collins et al., 2017). In addition to increased productivity, Chevron found that a single business unit was able to eliminate 100 hours of metrics reporting that would otherwise be redundant given the traditional analytics model (Collins et al., 2017). Furthermore, Chevron's analytics team was able to design customized attrition models per country to predict "future talent supply and demand" across its different business locations (Lewis, 2017). When testing this action-oriented attrition model, Chevron 
HR ANALYTICS AND STRATEGY

calculated it could predict outputs with $85 \%$ accuracy (Lewis, 2017). Chevron's analytics team has demonstrated its ability to effectively use data to forecast attrition while saving in-house costs for the function. (Table 4 summarizes the findings from all cases reviewed in this thesis.)

Table 4. Summary of Case Study Findings.

\begin{tabular}{|l|l|l|}
\hline Company & Effects on firm performance & $25-26$ \\
\hline Google & Interviewing efficiency & $29-30$ \\
\hline IBM & Reduced attrition & $34-35$ \\
\hline Starbucks & Customer satisfaction & $37-38$ \\
\hline Sestaurant.com & N/A & $42-43$ \\
\hline Jack in the Box & Reduced attrition and cost savings & $48-49$ \\
\hline Convergys & Attrition, productivity, cost savings, customer satisfaction & $49-50$ \\
\hline AC Milan & Reduced attrition and cost savings & $50-51$ \\
\hline Chevron & High-performance recruitment, reduced attrition & $51-52$ \\
\hline
\end{tabular}

\section{Discussion}

In summation, HR analytics has been defined in different ways, and its effectiveness has been investigated in different ways. As I note in this thesis, many sources failed to define and operationalize HR analytics, and those that did offered a variety of different definitions, ranging in levels of complexity regarding the inclusion of descriptive, predictive, and prescriptive analytics. Further, on the one hand, there is a paucity of peer-reviewed scholarly research investigating the potential causal impact of a well-defined and -integrated HR analytics function on firm performance and other outcomes. Decades of accumulated research industrial and organizational psychology, HR and organizational behavior, and strategic HRM, however, imply 
HR ANALYTICS AND STRATEGY

that using data to inform, support, and evaluate HR practices and systems can have important implications for employee and organizational outcomes. Nonetheless, in the context of scholarly literature, the questions remain: Do organizations with a HR analytics function outperform organizations that lack such a function? And how might the way in which a HR analytics function is defined and operationalized within organizations influence the effectiveness of the function when it comes to employee and organizational outcomes? On the other hand, as I have reviewed, various case studies and non-peer-reviewed, practitioner-oriented sources (e.g., news magazines, blogs) have offered and described how HR analytics might contribute to organizational outcomes or how specific organizations have found successes by designing, developing, and implementing a HR analytics function. Thus, the scholarly literature on HR analytics has seemingly fallen behind when it comes to evaluating how HR analytics is being applied and leveraged in organizations today to realize strategic objectives and attain a competitive advantage.

In this thesis, I have reviewed different considerations that pertain to the design, development, and implementation of a HR analytics. I discussed that a HR analytics function should operate synchronously with and integrate with other business functions to achieve desired business outcomes. Before investing any time and resources into HR analytics, HR leaders and senior leadership should be in agreement as to the strategic value and expected outcomes the function will deploy. More specifically, care should be taken when developing and designing a HR analytics function. The COM model, LAMP framework, and BASP framework are three examples that I reviewed that might be of value for HR professionals. Specifically, HR professionals can leverage these frameworks when strategizing and planning for a HR analytics 
HR ANALYTICS AND STRATEGY

function. HR leaders that facilitate the change-management process should maintain open communication with employees, explain the reasoning behind critical changes, anticipate pushback, and be eager to address feedback. During the implementation process, business leaders should allocate resources accordingly to ensure the best possible outcomes including the development of analytic competencies, time and space, financial investments, and effective data sharing that leverages appropriate information systems and technology. Lastly, proper evaluation must take place to hold leadership accountable, correct potential set-backs, and link HR-analytic investments with expected (and potentially unexpected) business results.

In terms of HR analytics impact on firm performance, based on the nine case studies I reviewed, one can conclude that there is some firm-specific evidence that HR analytics may lead to financial gain, reduced employee attrition, improved customer satisfaction and/or cost savings (Harris \& Light, 2011; Morgan, 2017; Schiemann \& Seibert, 2017). Across all nine of the cases, reduced attrition and cost savings appear to be the most common metrics used to improve firm performance. Despite these case studies and research in literature, it is inconclusive whether these findings generalize to other organizations, as there is (as described above) a paucity of research investigating a causal relationship between HR analytics and firm performance (Angrave et al., 2016; Marler \& Boudreau, 2017; Mondore et al., 2011; Rasmussen \& Ulrich, 2014).

\section{Limitations of Present Review}

While conducting my review of the extant literature, I found there to be relatively little scholarly research and literature specifically on HR analytics functions and their intersection with firm outcomes, especially when compared to other branches of the HR management field. 
HR ANALYTICS AND STRATEGY

Today, however, there is no shortage of non-peer-reviewed articles, particularly those in the form of blog posts, organizational white papers, and non-refereed surveys conducted by companies.

With all that said, I must also note that HR analytics stems from other disciplines (e.g., industrial and organizational psychology, strategic HRM, statistics, data science), and thus certain techniques associated with and components of HR analytics have received scholarly, peerreviewed empirical support over the years.

As another limitation, many organizations that claim to successfully manage a HR analytics function also present limited details as to how it operates, given the competitive nature of proprietary information (McKeon, n.d.). This poses a challenge to other companies seeking to learn more about HR analytics deployment from their counterparts. While several studies focus on industry-specific effects of HR analytics (e.g., Chadwick et al., 2015; Isson \& Harriot, 2012; Walsh et al., 2010), there is a limited number of research on the effects of HR analytics per industry usage.

As mentioned in the beginning of this thesis, the extant literature lacks an established definition of HR analytics; this can result in inconclusive analysis on HR analytics implementation and its impact on business performance. And as I have noted in several instances, there also appears to be a gap between scholarly research and the work currently conducted by practitioners and professionals in the area of HR analytics. This suggests a lack of communication between the two discourse communities which could be contributing to lapses in progression of HR analytics research. As I reported above in Tables 1 and 2, I categorized sources in this paper according to publication type. Among the literature reviewed, peerreviewed (20) and practitioner (15) journals were given more weight in the analysis followed by 
HR ANALYTICS AND STRATEGY

books (13). The additional 23 sources include blog posts, white papers, news articles and popular magazines which contributed to the discussion on HR analytics, strategic HRM, and other similar topics. It is important to note that although more peer-reviewed articles were selected, practitioner journals were referenced more throughout the analysis. Generally speaking, practitioner journals appear to be advancing quicker when evaluating HR analytics, whereas peer-reviewed journals seem to be slower to evaluate the impact of HR analytics and more cautious with assessments on HR analytics' impact on organizational performance.

Lastly, there is lack of literature that actively addresses a popular theoretical model referred to as the black box of HRM. This model dates back to the mid-1990s and suggests an explanation for the skepticism towards HR analytics adoption (see Figure 5) (Boselie, Dietz, \& Boon, 2005; Walsh et al., 2010). The black box of HRM points to the mystery of the processes that occur in terms of linking HR initiatives with business performance outcomes (Boselie et al., 2005). This model demonstrates the ongoing need for empirical evidence of a direct relationship between HR analytic inputs and it impact on a firm's bottom-line performance. For example, some scholars have suggested that HR systems appear to enhance performance but raise concerns towards the actual factors that enhance firm performance (Lepak et al., 2006; Marler \& Boudreau, 2017). Furthermore, the black box of HRM is referenced across literature in many instances without explicitly referring to it by name (Angrave et al., 2016; Bassi, 2011; Marler \& Boudreau, 2017; Rasmussen \& Ulrich, 2014). Once academics and practitioners work together to tackle the concern of the black box of HRM head-on, the mystery of HR analytics' impact on organizational strategic value and firm performance may unfold with greater clarity. 


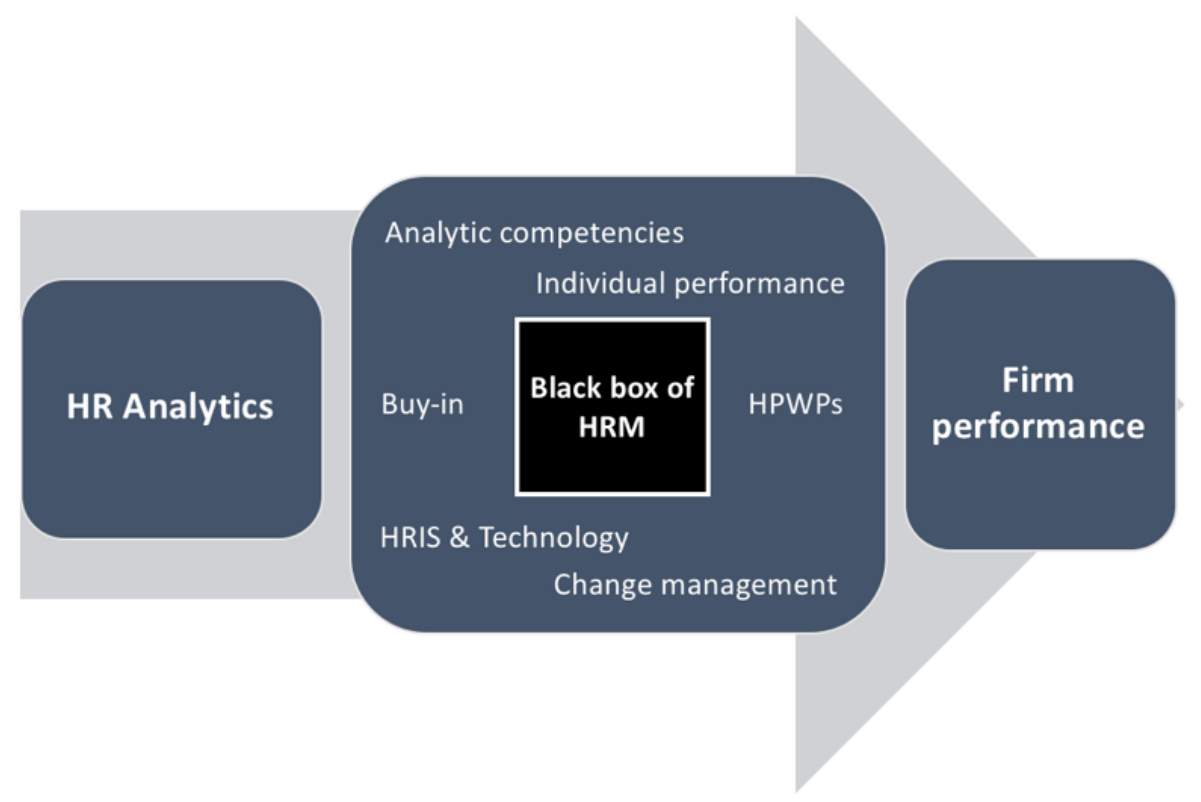

Figure 5. Black box of HR management (HRM) (adapted from Boselie et al., 2005; Walsh et al., 2010); note that HPWPs refers to high performance work practices.

\section{Future Directions for Science and Practice}

After conducting the literature review, I have observed that many sources surrounding the topic of HR analytics tend to criticize organizations that have not yet implemented it in their business as "behind-the-times" or lacking innovation (Dorio et al., 2014; Isson \& Harriot, 2012). However, the roles of administrative human resources and services should not be considered as obsolete (i.e., companies still need to process payroll, investigate employee engagement concerns, administer benefits). The difference is that now organizations have an opportunity to develop HR professionals who can work as strategic business partners and potentially leverage HR analytics for improved business decisions (Boudreau \& Ramstad, 2007). Interestingly, after conducting the above literature review, a recent global survey found a significant regression of 
HR ANALYTICS AND STRATEGY

HR departments' ability to use analytic tools effectively (Sinar, 2018; Thibodeau, 2018). Rather concluding HR analytics is destined to fail, the results of this survey suggest a need for further development in the skills and competencies of HR professionals regarding their ability to use data-analytic tools and interpret findings in a meaningful way. That is, it seems that the failure of HR analytics in some companies may have more to do with the lack of data-analytic capabilities of HR professionals.

To address this issue, the field of HR can begin focusing on how students are trained in HR at the university level and how organizations train and develop their HR professionals. In recognition of the relative lack of data-analytic training specifically for university HR students, Burris (2016) and Bauer and Caughlin (2017) developed a graduate course and an undergraduate course, respectively that teach students how to collect, manage, analyze, and interpret data in a HR context. In organizations, leadership has an opportunity to invest in its HR professionals by selecting HR professionals with data-analytics skills and competencies, and by providing extensive training and development opportunities in these areas. To encourage success, Collins et al. (2017) recommended gathering a multidisciplinary group of stakeholders who range in skills beyond technical analyses such as "data quality, business knowledge, data visualization and consulting" in addition to planning an investment roadmap for a company-wide function in analytics.

Given the aforementioned gaps in the literature, future research and academic publications should consider the extent to which storytelling and information and data visualization might influence how the design, development, and implementation of a HR analytics function is communicated to stakeholders. Current literature suggests these tools may 
HR ANALYTICS AND STRATEGY

be leveraged to eliminate potential barriers to understanding analytics, therefore helping HR professionals and other stakeholders to build support for a HR analytics function.

Finally, researchers should also conduct more systematic, empirical studies regarding the impact of HR analytics on firm performance. Angrave et al. (2016) suggested that more experiments and "quasi-experiments" that identify the cause-effect relationships of HR analytics on firm performance can lead to more valuable insight (p. 4). In addition, case studies can be analyzed further to uncover factors contributing to successful deployment of HR analytics in organizations to inform and inspire future research.

\section{Conclusion}

The overarching purpose of this paper was to provide an in-depth analysis of the extant literature regarding HR analytics, strategic HRM, and their impact on firm performance. Because companies often invest large amounts of resources in developing and implanting HR practices and systems, they can potentially improve their decision-making processes in this area by using data to inform decisions. As such, organizations can build on the findings of this paper to make an educated decision as to how their business might benefit from a HR analytics function and what the implementation process may entail. Academic scholars should work closely with organizational leaders to communicate new and important findings regarding HR analytics. To that end, there are numerous case studies and non-peer-reviewed sources that tout the benefits of HR analytics with respect to firm performance; however, the scholarly peer-reviewed literature has yet to catch up with systematic investigations targeting the extent to which HR analytics, in the different forms it is applied today, lead to valued organizational outcomes. 
HR ANALYTICS AND STRATEGY

Throughout the paper, HR analytics is referenced in conjunction with strategic HRM. This partnership indicates that it is the combination of the two that is required for organizations to achieve competitive advantage. Other essential factors include resource orchestration, high performance work practices and commitment-based HR systems. Case studies are embedded throughout the thesis to demonstrate the potential real-world practicality and effectiveness of a HR analytics function. Commons metrics used for calculating HR analytic impact on firm performance include reduced attrition, improved customer satisfaction and cost savings, measured in terms of financial gains. Academics and organizational leaders are encouraged to continue developing solutions to more effectively deploy HR analytics in business for the purposes of attaining of strategic objectives and a competitive advantage. 
HR ANALYTICS AND STRATEGY

\section{References}

Alharthey, B. K., \& Rasli, A. (2011). Key role of strategic human resource management (SHRM) in advancing the degree of team learning. African Journal of Business Management, 5(26), 10446-10451.

Angrave, D., Stuart, M., Charlwood, A., Kirkpatrick, I., \& Lawrence, M. (2016). HR and analytics: Why HR is set to fail the big data challenge. Human Resource Management Journal. 26 (1), 1-11.

Barrette, J. (2015). Workforce Analytics: Achieving the Action Reaction. Workforce Solutions Review, 11-14.

Barton, D., Court, D. (2012). Making Advanced Analytics Work For You. Harvard Business Review, 90 (10), 78-83.

Bassi, L. (2011). Raging debates in HR analytics. People \& Strategy, 34 (2), 15-17.

Bates, S. (2003). The metrics maze. HR Magazine, 48 (12), 1-6.

Bauer, T., \& Caughlin, D. (2017). HR information systems 2.0: Integrating people analytics. Re:Work. Retrieved from: https://rework.withgoogle.com/blog/HRIS-2-integratingpeople-analytics/

Beatty, R. (2005). The New Frontier for Competitive Advantage. Convergys Corporation, 1-15. Retrieved from: http://agilityconsulting.com/wp-content/uploads/2013/04/UnivMichWorkforce-Agility.pdf

Becker, B. E., Huselid, M. A., \& Ulrich, D. (2003). The HR scorecard: Linking people, strategy, and performance. Boston, MA: Harvard Business School Press.

Bock, L. (2015). Work Rules! That will transform how you live and lead. New York, NY: 
HR ANALYTICS AND STRATEGY

Twelve.

Boselie, P., Dietz, G. \& Boon, C. (2005). Commonalities and contradictions in HRM and performance research. Human Resource Management Journal, 15 (3): 67-94.

Boudreau, J. \& Ramstad, P. (2007). Beyond HR. The new science of human capital. Boston: Harvard Business School Press.

Brown, M. G. (2013). Killer Analytics: Top 20 Metrics Missing from Your Balance Sheet. Hoboken, NJ: John Wiley \& Sons.

Burris, E. (2016). Let's use people analytics to change how we teach HR. Re:Work. Retrieved from: https://rework.withgoogle.com/blog/use-people-analytics-to-change-how-we-teach$\underline{\mathrm{HR} /}$

Campion, M. A., \& McClelland, C. L. (1991). Interdisciplinary examination of the costs and benefits of enlarged jobs: A job design quasi-experiment. Journal of Applied Psychology, 76(2), 186-198.

Carlson, K. D., \& Kavanagh, M. J. (2015). HR metrics and workforce analytics. In M. J. Kavanagh, M. Thite, \& R. D. Johnson (Eds). Human Resource Information Systems: Basics applications and future directions, 2nd edition, Chapter 6, (150-174). Thousand Oaks, CA: Sage

Cascio, W., \& Boudreau, J. (2011). Investing in people: Financial impact of human resource initiatives (2nd Ed.). Saddle River, NJ: Pearson Education, Inc.

Caughlin, D. E. (in press). People analytics. In R. Griffin (Ed.), Oxford bibliographies in management studies. New York, NY: Oxford University Press. 
HR ANALYTICS AND STRATEGY

Chadwick, C., Super, J., \& Kwon, K. (2015). Resource orchestration in practice: CEO emphasis on SHRM, commitment-based HR systems, and firm performance. Strategic Management Journal, 36, 360-376.

Collins, L., Fineman, D. R., \& Tsuchida, A. (February 28, 2017). People analytics: Recalculating the route. Retrieved from https://www2.deloitte.com/insights/us/en/focus/human-capitaltrends/2017/people-analytics-in-hr.html\#endnote-sup-16.

Combs, J., Liu, Y., Hall, A., \& Ketchen, D. (2006). How much do high-performance work practices matter? A meta-analysis of their effects on organizational performance. Personnel Psychology, 59, 501-528.

Davenport, T. (2012). Data Scientist: The Sexiest Job Of the 21st Century. Harvard Business Review, 90 (10), 70-76.

Davenport, T.H., Harris, J., \& Shapiro, J. (2007). Competing on talent analytic. Harvard Business Review, 88 (10), 2-6.

De Treville, S., \& Antonakis, J. (2006). Could lean production job design be intrinsically motivating? Contextual, configurational, and levels-of-analysis issues. Journal of Operations Management, 24(2), 99-123.

Deloitte's Bersin Finds Effective Use of People Analytics Is Strongly Related to Improved Talent and Business Outcomes (2017). In Deloitte Consulting LLP's press release. Retrieved from: https://www.bersin.com/deloittes-bersin-finds-effective-use-peopleanalytics-strongly-related-improved-talent-business-outcomes-2/

Dobbs, J., Madgavkar, A., Barton, D., Labaye, E., Manyika, J., Roxburgh, C., Lund, S., Madhav, 
HR ANALYTICS AND STRATEGY

S. (2012). The world at work: Jobs, pay, and skills for 3.5 billion people. McKinsey Global Institute.

Dorio, J., Rasch, R., Feinzig, S. (2014). Are traditional HR practices keeping your organization average? Build a high-potential organization with workforce science. IBM Smarter Workforce Institute.

Edwards, M. R., \& Edwards, K. (2016). Predictive HR analytics: Mastering the HR metric. New York, NY: Amacom.

Falletta, S. (2014). In search of HR intelligence: evidence-based HR analytics practices in high performing companies. People \& Strategy. 36, 4: 28-37.

Fitz-enz (2010). The new HR analytics: Predicting the economic value of your company's human capital investments, AMACOM Div American Management Association.

Fitz-Enz, J., \& Mattox, J. R. (2014). Predictive analytics for human resources. Hoboken, NJ: Wiley.

Future Insights: the top trends according to SHRM's HR subject matter expert panels (2009). In SHRM Research report. Retrieved from: shrm.org/research

Gale, S. (2015). Predict (still in) the future. Human Resource Management Systems, 44-47.

Harris, E. C., \& Light, D. A. (2011). Talent and analytics: new approaches, higher ROI, Journal of Business Strategy, 32(6), 4-13.

Heskett, J. L., Jones, T. O., Loveman, G.W., Sasser, W. E., \& Schlesinger, L. A. (2008). Putting the service-profit chain to work. Harvard Business Review.

HR analytics (n.d.) IBM website. Retrieved from: https://www-01.ibm.com/software/analytics/solutions/operational-analytics/hr-analytics/ 
HR ANALYTICS AND STRATEGY

Humphrey, S. E., Nahrgang, J. D., \& Morgeson, F. P. (2007). Integrating motivational, social, and contextual work design features: A meta-analytic summary and theoretical extension of the work design literature. Journal of Applied Psychology, 92(5), 1332-1356.

Hunt, S. (2014). Common sense talent management: Using strategic human resources to improve company performance. San Francisco: John Wiley \& Sons, Incorporated.

Huselid, M. A. (1995). The impact of human resource management practices on turnover, productivity, and corporate financial performance. Academy of Management Journal, 38, $635-672$.

IBM Watson Talent Insights (n.d.). IBM Marketplace website. Retrieved from: https://www.ibm.com/us-en/marketplace/workforce-analytics

Isson, J. P., Harriott J. S. (2013). Win With Advanced Business Analytics: Creating Business Value From Your Data. Hoboken, NJ, USA: Wiley.

Jackson, S., Schuler, R. \& Jiang, K. 2014. An aspirational framework for strategic human resource management. The academy of management annals. 8, 1: 1-56.

Jenks, S. (2017, June 7). Pet insurance is the latest work perk. The New York Times. Retrieved from https://www.nytimes.com/2017/06/07/well/family/pet-insurance-is-the latest-work-perk.html

Jiang, K., Lepak, D. P., Hu, J., \& Baer, J. C. (2012). How does human resource management influence organizational outcomes? A meta-analytic investigation of mediating mechanisms. Academy of Management Journal, 55(6), 1264-1294.

Kaur, J., \& Fink, A. A. (2017). Trends and practices in talent analytics. Society for Human Resource Management (SHRM)-Society for Industrial-Organizational Psychology 
HR ANALYTICS AND STRATEGY

(SIOP) Science of HR White Paper Series.

Khoso, M. (2016). Data Analytics in the Real World: Starbucks. Northeastern University. Retrieved from: http://www.northeastern.edu/levelblog/2016/03/04/data-analytics-in-the real-world-starbucks/

Lawler, E., Levenson, A., Boudreau, J. (2004). HR Metrics and Analytics - Uses and Impacts. Center for Effective Organisations, University of Southern California.

Levenson, A. (2010). Using targeted analytics to improve talent decisions. People and Strategy, 34(2), 3-22.

Lewis, G. (March 30, 2017). 3 ways data shapes the talent strategy at Tesla, Chevron, and LinkedIn. Retrieved from: https://business.linkedin.com/talentsolutions/blog/talentanalytics/2017/3-ways-datashapes-the-talent-strategy-at-tesla-chevron-and-linkedin.

Marler, J., \& Boudreau, J. (2017). An evidence-based review of HR analytics. The International Journal of Human Resource Management, 28 (1), 3-24.

McAfee, A. \& Brynjolfsson, E. (2012). Big data: the management revolution. Harvard Business Review, 60-69.

McKeon, A. (n.d.). How some companies reap rewards of people analytics tools. Retrieved from http://searchhrsoftware.techtarget.com/feature/How-some-companies-reap-rewardsofpeople-analytics-tools.

Molefe, M. (2013). From data to insights: HR analytics in organisations. University of Pretoria. Mondore, S., Doutitt, S., \& Carson, M (2011). Maximizing the impact and effectiveness of HR analytics to drive business outcomes. People \& Strategy, 34(2). 21-27. 
HR ANALYTICS AND STRATEGY

Morgan J. (2017). The Employee Experience Advantage: How to Win the War for Talent by Giving Employees the Workspaces They Want, the Tools They Need, and a Culture They Can Celebrate. NY: John Wiley \& Sons Inc.

New Bersin by Deloitte Research Shows Organizations with High-Impact Talent Analytics Realize Major Financial, Leadership, and Recruitment Gains. (2013). In PR Newswire's Communications and Mass Media Collections. Retrieved from: http://link.galegroup.com.proxy.lib.pdx.edu/apps/doc/A344905802/PPCM?u=s1185784\& $\underline{\text { sid }=P P C M \& x i d=f d 3855 d 3}$

Pease, G. (2015). Optimize your greatest asset - your people: How to apply analytics to big data to improve your human capital investments. Hoboken, NJ: Wiley.

Pemmaraju, S. (2007). Converting HR data to business intelligence. Employment Relations Today, 34(3), 13-16.

People analytics at Google: using data to make Google a great place to work (2017). In Digital Innovation and Transformation, a course at Harvard Business School. Retrieved from: https://digit.hbs.org/submission/people-analytics-at-google-using-data-to-make-google-agreat-place-to-work/

Pfau, B., \& Cohen, S. (2003). Aligning human capital practices and employee behavior with shareholder value. Psychology Journal: Practice and Research, 55 (3), 169-178.

Pfeffer, J., \& Veiga, J. (1999). Putting People First for Organizational Success. The Academy of Management Executive (1993-2005), 13(2), 37-48.

Rasmussen, T., \& Ulrich, D. (2015). Learning from practice: How HR analytics avoids being a management fad. Organizational Dynamics, 44(3), 236-242. 
HR ANALYTICS AND STRATEGY

Rousseau, D. \& Barends, E. 2011. Becoming an evidence-based HR practitioner. Human Resource Management Journal, 21(3): 221-235.

Schiemann, W., \& Seibert, J. (2017). Winning the HRM Evidence-Based Impact Award Lessons Learned: A Conversation with Key Stakeholders to the Process. Industrial and Organizational Psychology, 10(2), 314-326.

Sinar, E. (2018). People Analytics: Reversal of Fortunes. In Development Dimensions International, Inc.'s Global Leadership Forecast. Retrieved from: https://www.ddiworld.com/glf2018/people-analytics

Smith, J. (2016, February 3). 20 incredible perks companies like Airbnb, Facebook, and Google offer their employees. Business Insider. Retrieved from http://www.businessinsider.com/incredible-perks-companies-like-airbnb-facebook-and google-offer-their-employees-2016-2

Sullivan, J. (2013). How Google is using people analytics to completely reinvent HR. TLNT: The Business of HR, 26.

Taylor, S., Beechler, S., Napier, N. (1996) Toward an Integrative Model of Strategic International Human Resource Management. The Academy of Management Review, 21(4), 959-985.

The Dollars and Sense of Employee Engagement, Calculate Your ROI (2017) Talent Map. Retrieved from https://www.talentmap.com/calculate-employee-engagement-roi/

Thibodeau (2018). HR is failing to use people analytics tools, new report says. TechTarget. Retrieved from: http://searchhrsoftware.techtarget.com/news/252435104/HR-is-failingto-use-people-analytics-tools-new-report-says 
HR ANALYTICS AND STRATEGY

Ulrich, D. Schiemann, W., Sartain, L. (2015) The rise of HR: Wisdom from 73 thought leaders. Alexandria, VA: HR Certification Institute.

Van den Heuvel, S., \& Bondarouk, T. (2017). The rise (and fall?) of HR analytics: a study into the future application, value, structure, and system support. Journal of Organizational Effectiveness: People and Performance, 4(2), 157-178.

Walsh, K., Sturman, M., Longstreet, J. (2010) Key issues in strategic human resources. The Scholarly Commons. School of Hotel Administration Collection.

Welbourne, T. (2015). Data-driven storytelling: the missing link in HR data analytics. Employment Relations Today, 41 (4), 27-33.

Witte, L. (2016). We have HR analytics! So what? - An exploratory study into the impact of HR analytics on strategic HRM. University of Twente, 1-46. 